\title{
Deviations From Standard Family Histories and \\ Subjective Wellbeing at Older Ages
}

\author{
Bruno Arpino \\ University of Florence \\ Department of Statistics, Computer Science, Applications \\ Viale Morgagni 59, 50134 Firenze (Italy); bruno.arpino@unifi.it \\ Jordi Gumà \\ Pompeu Fabra University \\ Department of Political and Social Sciences \\ Carrer Ramon Trias Fargas 25-27, 08005 Barcelona (Spain); jordi.guma@upf.edu
}

\author{
Albert Julià \\ University of Barcelona \\ Department of Sociology \\ Avinguda Diagonal 690-696, 08034 Barcelona (Spain) albert.julia.cano@ub.edu
}

\begin{abstract}
Life course research emphasizes that health and wellbeing at older ages are influenced by experiences occurred in the previous stages of life. Several studies have focused on fertility and partnership histories and health at older ages, but fewer have examined subjective wellbeing (SWB), especially using a holistic approach. Another strand of the literature demonstrated that non-standard family behaviors negatively influence SWB. We contribute to these strands of the literature by examining the association between non-standardness of family histories and SWB at older ages. We argue that individuals who experienced nonstandard trajectories have been exposed to social sanctions throughout their life course which could exert negative long-term influence on their SWB.
\end{abstract}


We apply sequence analysis and optimal matching on retrospective data from the seventh wave of the Survey of Health Ageing and Retirement in Europe (SHARE) to calculate the degree of non-standardness of family histories between age 15 and 49 . Subsequently, we estimate linear regression models to assess the association between nonstandardness of family histories and older people's SWB. Our results show a negative association between non-standardness of family histories and SWB, which is stronger for lower educated individuals and in Southern European countries.

Keywords: Fertility histories; Partnership histories; subjective wellbeing; older people; SHARE.

\section{Acknowledgments:}

The members of the University of Florence Population and Society Unit (UPS), in particular Giammarco Alderotti, Valentina Tocchioni and Daniele Vignoli, are gratefully acknowledged for useful comments on a preliminary version of the study. We are also grateful for comments received at seminars (at the Centre for Demographic Studies (CED, Barcelona - Spain), Centre for Population Change (CPC, Southampton - UK), Center for Social Inequality Studies (Trento - Italy)) and conferences (European Population Conference 2018 (Brussels Belgium); $12^{\text {th }}$ Italian Population Days (Florence - Italy)). This study belongs to the multicountry project "Care, Retirement \& Wellbeing of Older People Across Different Welfare Regimes" (CREW). The authors acknowledge funding from the Spanish Ministry of Economy, Industry and Competitiveness (PCIN-2016-005; PI: Bruno Arpino) within the second Joint Programming Initiative "More Years Better Lives". 


\section{Introduction}

Against the background of population aging and demographic changes occurred in the past decades, the extent to which fertility and partnership behaviors produce long-term consequences on subjective wellbeing at older ages is increasingly of concern. Within the life course framework, it has been theorized that older adults' health and subjective wellbeing (SWB) are influenced by events and experiences occurred throughout the different life stages (Barker 2004; Ben-Shlomo and Kuh 2002; Carr and Utz 2020; Hayward and Gorman 2004; Kuh et al. 2018; Pudrovska and Anikputa 2014; Umberson and Thomeer 2020) and a spate of studies have reported substantial effects of fertility and partnership histories on health, healthy behaviors and mortality (Barclay et al. 2016; Grundy and Tomassini 2010; Grundy and Kravdal 2010; Grundy and Holt 2000; Hank 2010; Quashie et al. 2021; Reczek et al. 2016; Sironi 2019; Sironi et al. 2020). Part of this literature adopted a holistic approach to the analysis of family histories by accounting for both occurrence and timing of fertility and partnership events (e.g., Barban 2013; Kravdal et al. 2012; O'Flaherty et al. 2016; Sabbath et al. 2015), thus recognizing the dynamic interdependencies among these processes (Macmillan and Copher 2005). Numerous works exists that have examined SWB rather than health or mortality, usually either focusing on number of children or partnership status (e.g., Be et al. 2013; Becker et al. 2019; Margolis and Myrskylä 2011). More rarely these studies have accounted also for other aspects such as timing of transition to parenthood and union formation/dissolution and the interdependencies between fertility and partnership histories (for exceptions, see e.g., Comolli et al. 2021; Lacey et al. 2016).

Another strand of the literature has focused on understanding the extent to which individuals who experience "non-standard" (i.e., uncommon) demographic behaviors report lower wellbeing as compared to those who behave in a more common way (Kalmijn 2010; Koropeckyj-Cox et al. 2007; Pirani and Vignoli 2016; Soons and Kalmijn 2009; Stavrova and 
Fetchenhauer 2015; Verbakel 2012; Zoutewelle-Terovan and Liefbroer 2018). The Second Demographic Transition (SDT) theory described changes in demographic behaviors occurred in Europe since the 1950s and identified ideational changes as the main force behind the postponement of marriage and parenthood, fertility reduction, the rise of alternative forms of partnerships, and parenthood outside marriage (van de Kaa 1994; Lesthaeghe 2020; Surkyn and Lesthaeghe 2004). Instead, the consequences of "family de-standardization" (Espenshade 1985) and of the adoption of non-standard demographic behaviors on individuals' wellbeing have been usually interpreted adopting the life course perspective or the institutionalization framework as related to the existence of social norms that influence demographic behaviors (Liefbroer and Billari 2010). The key idea in the studies on the consequences of non-standard demographic behaviors on wellbeing is that individuals may be exposed to social, emotional and economic sanctions if they adopt uncommon behaviors (Soons and Kalmijn 2009). These studies have usually focused on adult individuals, rather than on older people, did not account for longer-term consequences on wellbeing at older ages, and considered specific events/behaviors, such as cohabitation or divorce.

Our study aims to contribute to the strands of the literature mentioned above. Specifically, drawing insights from both of them and using data from Survey of Health, Ageing and Retirement in Europe (SHARE), we examine the association between the degree of non-standardeness of family histories during adulthood (ages 15-49) and SWB at older ages (50-85). We adopt a holistic approach and examine how fertility and partnership histories considered together influence subjective wellbeing in later life. Our approach, based on sequence analysis, allows us to take into account simultaneously quantum and timing of both fertility and partnership histories. Based on optimal matching, we consider the distances between each individual family history and those of the other respondents in the same reference group defined by the combination of country, birth cohort and gender. This permits 
to account for variation in family histories across these three dimensions that are also likely related to different norms and social sanctions (Merton, 1968; Montgomery and Casterline 1996). The distances are averaged within the reference groups, thus building a relative measure of non-standardeness of family histories that in regression analysis constitutes our explanatory variable. Additionally, we examine heterogeneities in the association between of non-standardeness of family histories and SWB depending on gender, education and country groups. Heterogeneities in the effects of non-standard family behaviors have not been assessed in previous studies on older people's SWB.

Before moving forward, it is important to mention that an association between the degree of non-standardness of family histories and SWB at older ages may be due to selection mechanisms. Early-life disadvantages in terms of poor health and low socioeconomic status have been shown to both shape the likelihood of individuals experiencing "deviating" demographic behaviors and to display long-lasting associations with health and wellbeing at older ages (Arpino et al. 2018b; Grundy and Tomassini 2010; Hayward and Gorman 2004; Perelli-Harris et al. 2019; Pudrovska and Anikputa, 2012; Pudrovska and Anikputa 2014); Sironi et al. 2020). Therefore, following other studies on life course histories and health and wellbeing (Comolli et al. 2021; Henretta 2007; O'Flaherty et al. 2016), in order to rule-out, as much as possible, the possibility that selection factors rather than the non-standardness of family histories are the main drivers behind the association under study, our analyses will account for several early-life conditions measured retrospectively.

\section{Background}

An increasing body of research has focused on the interplay between wellbeing and fertility (Balbo and Arpino, 2016; Billari 2009; Conzo et al. 2017; Kohler and Mencarini 2016; Myrskylä and Margolis, 2014) or partnership status (Brown 2000; Kim and McKenry 2002; 
Perelli-Harris et al. 2019; Soons et al. 2009; Waite and Gallagher 2000; Wright and Brown 2017). While demographic studies have mostly focused on subjective wellbeing (SWB; typical indicators have included life satisfaction and happiness), research in allied fields (e.g., family sociology and social gerontology) have more frequently considered psychological wellbeing (PWB) more broadly, including, for example, measures of depressive symptoms and quality of life. Despite the different conceptual nature of the several measures, they tend to be correlated and associations with family histories are often similar (e.g., Becker et al. (2019); but see e.g. Deaton and Stone (2014) for exceptions). Below, we will mostly refer to previous studies on SWB, unless differently noticed. Our main analyses examine life satisfaction, but in additional analyses we also consider other measures.

\section{Fertility, Partnership and Subjective Wellbeing}

Cross-sectional research on fertility and SWB found mixed evidence (Aassve et al. 2012; Margolis and Myrskylä 2011), possibly because of the combination of costs and rewards implied by childbearing (Nomaguchi and Milkie 2003). Instead, more recent longitudinal studies tend to report positive associations between SWB and transition to parenthood and to, a lesser extent, to higher order parities, but these effects are heterogeneous and usually limited to the years surrounding the childbearing events (Balbo and Arpino 2016; Myrskylä and Margolis 2014). Differently from this evidence of limited benefits from childbearing that emerges on adult individuals, in later life parents usually show higher SWB compared to their childless counterparts, and at older ages SWB tends to increase with the number of children (Becker et al. 2019; Margolis and Myrskylä 2011), but evidence of null differences also exists (see e.g., Hank and Wagner 2013 on depression). Comparing different age groups, Margolis and Myrskylä (2011) found that the association between SWB and fertility evolves 
from negative to neutral to positive above age 40, and it is strongest among the oldest individuals.

The association between partnership status and SWB has also attracted considerable attention. Although exceptions exist, and despite heterogeneities in the wellbeing-partnership relationship, research tends to suggest a gradient both in SWB (Kalmijn 2010; Margolis and Myrskylä 2011; Mikucka 2016, Pirani and Vignoli 2016, Soons and Kalmijin 2009; Verbakel 2012) and other measures of PWB (Brown 2000; Gumà and Fernández-Carro 2021; Kim and McKenry 2002; Koropeckyj-Cox et al. 2007; Wright and Brown 2017) with married people enjoying the highest level of wellbeing, followed by cohabiting, single, and finally widowed and divorced individuals. As long as the relationship with the partner does not falter, a partnership represents a source of fulfillment and support, thus increasing partners' SWB both among adults and older people (Be et al. 2013; Carr and Utz 2020). In fact, although studies point to a rising pattern of SWB around entry into a union followed by a slow decrease, the partnership premium in terms of SWB, on average, persists over time in the absence of relationship conflicts (e.g., Soons et al. 2009; Zimmermann and Easterlin 2006). When a union is dissolved, the negative effects on partners' SWB tends to be mostly evident in the short run (Soons et al. 2009), but studies on older people report lower SWB (Arpino et al. 2018a; Margolis and Myrskylä 2011; Solé-Auró and Cortina 2019) or other measures of PWB (Wright and Brown 2017; Zoutewelle-Terovan and Liefbroer 2018) among divorced/separated individuals as compared to those in a partnership.

The timing of fertility and partnership events has been less frequently examined in relation to wellbeing of older individuals. Studies on adults showed that for parents who have children at younger ages the costs associated with childrearing tend to outweigh the rewards leading, more likely than for older parents, into negative childbearing effects. In other words, the effect of fertility tends to be more positive the higher is the age at childbearing (Myrskylä 
and Margolis 2014). This is consistent with research showing poorer health (e.g., Sironi et al. 2020) and PWB (Koropeckyj-Cox et al. 2007; Read and Grundy 2011) at older ages associated with early childbearing. Similarly, some studies report negative associations between early partnership formation and health (e.g., McFarland et al. 2013). As far as we are aware, only two studies have analyzed SWB at older ages accounting also for the timing of family histories, reporting negative (Comolli et al. 2021) or statistically insignificant effects (Lacey et al. 2016) of early family formation.

\section{Family Histories and Wellbeing: Interdependencies and Holistic Approaches}

Research adopting the life course perspective stressed that fertility and partnership are interdependent processes that should be examined together (Macmillan and Copher 2005), and that they interact in influencing wellbeing. Research has consistently found single parents to report lower SWB or PWB compared to married parents (Umberson et al. 2010); the opposite has been reported among widowed (Umberson and Gove 1989). Zhang and Hayward (2001) found that a negative association between childlessness and older people's PWB was apparent only among unpartnered men. Timing of fertility and partnership transitions are also strongly associated. For example, marriage at very young ages often precedes an early age at first birth (McFarland et al. 2013). Studies that empirically considered both timing of fertility and partnership histories found them to naturally "cluster" together according to the general timing of "family formation", and, as mentioned above, mixed evidence about the association with SWB has been found (Comolli et al. 2021; Lacey et al. 2016).

In addition to interdependencies between fertility and partnership histories, the life course perspective highlights the importance of adopting a holistic approach to the study of family histories in order to simultaneously account for several aspects (i.e., quantum, timing 
and sequencing of events), and numerous demographic studies have adopted Sequence Analysis (SA) for this purpose (Abbott 1995; Billari 2001). This approach has also been recently employed to examine family histories and health (O'Flaherty et al. 2016) and SWB at older ages (Comolli et al. 2021; Lacey et al. 2016). SA allows to parsimoniously represent the complexity of family life courses and to calculate the "social distance" between individuals (Abbott and Tsay 2000). These distances among individual life courses are typically summarized into a certain number of clusters, then examined in association with one or more outcomes. In our study, instead, the distances among individuals' family histories are of direct interest because they allow us measuring to what extent the family life course of an individual "deviates" from the common family histories experienced by others and whether the non-standardness of family histories is associated with SWB in later life.

\section{Non-standardness of Family Histories and Subjective Wellbeing}

The life course approach has emphasized the importance of norms in governing demographic behaviors, and more specifically their occurrence (e.g., experiencing divorce), quantum (e.g., number of children), timing ("age norms"; e.g., ages at which individuals should marry) and sequencing (e.g., having children after marriage) (Liefbroer and Billari 2010; Settersten 2003; Settersten and Hagestad 1996). Empirical research has provided evidence on the influence of norms on demographic behaviors (e.g., Billari and Liefbroer 2007; Hofäcker and Chaloupková 2014). Norms vary to certain extent over time and countries (Liefbroer and Merz 2009; Thornton and Young-DeMarco 2001), and social changes occurred during the second part of the past century have brought greater life course variability and acceptance of different life paths. Still, the relevance of norms for demographic behaviors has remained high (Liefbroer and Billari 2010), especially for the cohorts we consider in our analyses (individuals born between 1932 and 1962). 
Although this aspect is contested, it is prevailing the idea that a key characteristic of norms is that they are sustained by sanctions that include guilt, shame, economic costs, social disapproval and exclusion (Cherlin 2004; Liefbroer and Billari 2010; Posner and Rasmussen 1999). Approval from others is an important element of overall wellbeing (Lindenberg 2001); therefore, sanctions attached to non-standard behaviors may lead to a decline in SWB. In addition, feelings of guilt and shame, especially "external shame", which involves negative views of self as seen through the eyes of others, are associated with lower wellbeing (Kim et al. 2011).

When social norms are institutionalized, sanctions may even be inscribed into the legal system, in the form of legal obligations, prohibitions, or (dis)incentives (Liefbroer and Billari 2010; Soons and Kalmijin 2009). For example, in contexts where cohabitation is not widespread, cohabitors may not hold the same rights as married people, such as tax benefits (Soons and Kalmijin 2009). Thus, formal sanctions may be another channel leading to negative effects on SWB of non-standard demographic behaviors.

A large body of research has shown that adopting uncommon practices or beliefs might lead to lower wellbeing (Stavrova 2014), and evidence of negative consequences of non-conformity exists with respect to a large variety of life choices or conditions, including unemployment and atheism (Stavrova and Fetchenhauer 2015). Cross-country research, mostly focused on European countries, has also specifically found evidence that the adoption of non-standard demographic behaviors is associated with lower SWB. Cohabitors report lower SWB as compared to married individuals in countries with a low prevalence of cohabitation, and the gap tends to reduces with the diffusion of this type of partnership (Pirani and Vignoli 2016; Soons and Kalmijn 2009). Similar findings have been shown for divorce (Kalmijn 2010; Verbakel 2012), single parenthood (Stavrova and Fetchenhauer 2015) and childlessness (Huijts et al. 2013 - on depression; Zoutewelle-Terovan and Liefbroer 2018 
- on loneliness). All these studies have consistently found worse wellbeing associated with non-standard demographic behaviors, i.e. behaviors that were less common in a given context.

This strand of the literature has focused on adult individuals, rather than on older people, thus not accounting for longer term consequences on wellbeing at older ages. Also, this literature focused on specific behaviors, such as cohabitation, divorce or childlessness. An exception is Zoutewelle-Terovan and Liefbroer (2018) that examined, separately, lifelong singlehood, childlessness, and "off-time" family transitions during adulthood in relation to loneliness at older ages. Building on this study, and on holistic approaches to family histories, we examine how SWB at older ages is related to non-standardness of fertility and partnership histories considered simultaneously, and in their complexity (accounting for quantum, timing and sequencing of events). The degree of non-standardness will be considered with reference to the combination of country, birth cohort and gender, to account for the variability of demographic behaviors across these dimensions. Also, we address the heterogeneity in the consequences of adopting "deviating” behaviors by gender, education and country group.

\section{Heterogeneities in the Association Between Non-standardness of Family Histories and}

\section{Subjective Wellbeing}

The life course perspective underscores that the consequences of life events and circumstances are heterogeneous and vary with the social context to which individuals are exposed. Regarding social norms related to demographic behaviors research has accounted for gender differences. Certain norms may apply more stringently to women than to men (Settersten 2003; Settersten and Hagestad 1996). Although empirical evidence is missing for the cohorts under investigation in our study during their adulthood, in a context of gender inequalities that characterised their life courses it can be expected that "deviating" behaviors 
were more disapproved for women than for men, and sanctions attached to violations of norms might have also been stronger for women. However, research on gender double standards, i.e. a different evaluation of the same behaviour for women and men often found the opposite. For example, Rijken and Merz (2014) found that voluntary childlessness was more disapproved for men. Similarly, Rijken and Liefbroer (2016) report that behaviors such as having children in a non-marital union and divorce of parents received more disapproval for men. These studies have focused on more recent cohorts as compared to those we analyse, but they suggest that the consequences on SWB of non-standard demographic behaviors might be stronger for men. The existing empirical evidence on this aspect is mixed. Zhang and Hayward (2001) report a negative association between childlessness and older people's PWB for unpartnered men, but not for women. Similarly, Huijts et al. (2013)'s analyses indicate that for men the overall disadvantage in terms of PWB of being childless is stronger than for women. On the contrary, other studies have found non-standard family histories to have stronger negative effects on SWB for women (Comolli et al. 2021; Lacey et al. 2016). In addition, divorced and cohabiting women have been found to be more disadvantaged in terms of their SWB than married women, while the gaps were weaker for men (Stavrova and Fetchenhauer 2015; Verbakel 2012). Yet other studies found similar associations by gender between wellbeing and non-standard demographic behaviors (Kalmijn 2010; KoropeckyjCox et al. 2007; Soons et al. 2009; Zoutewelle-Terovan and Liefbroer 2018). Thus, we examine gender differences without formulating any expectation.

Education may potentially moderate the association between non-standard demographic behaviors and SWB. On the one hand, compared to individuals with a low level of education, highly educated individuals have more economic and cultural resources that may help buffer the negative consequences of sanctions related to non-standard behaviors, thus reducing subsequent stress (Thoits 1995). On the other hand, higher economic and 
cultural capital may influence the ability to comply to norms (Jensen and Bute 2010), so that for highly educated individuals the adoption of non-standard demographic behaviors, such as historically early adoption of cohabitation, may more likely be the resultant of choice rather than socio-economic disadvantage (Lesthaeghe 2020). In other words, “deviating” behaviors for highly educated individuals may more likely follow to planification and careful evaluation of costs and benefits. Thus, it is reasonable to expect the association between the degree of non-standardness of family histories and SWB to be weaker for individuals with higher levels of education. None of the previous studies that specifically addressed the consequences of non-standard family histories on SWB at older ages has tested the moderating role of education.

Finally, we examine whether the association between non-standardness of family histories and older people's SWB varies across the country context. As already noticed, family life courses vary across countries (Van Winkle 2018) also because of varying contextual norms (Lesthaeghe 2010). Here, however, and similar to what stated above for gender and education, we posit that the consequences of family histories, and more specifically their degree of non-standardness, on SWB may vary across countries. Countries differ in terms of cultural values, and in more "traditionalist" countries norms against nonstandard family behaviors (e.g., divorce, cohabitation, childlessness) tend to be stronger (Inglehart and Baker 2000). Correspondingly, the social and legal penalties attached to violations of these norms may be harsher (Zoutewelle-Terovan and Liefbroer 2018). The European setting of our study offers considerable cross-national variation in family-related norms (Hofäcker and Chaloupková 2014; Liefbroer and Merz 2009). One extreme is represented by Scandinavian countries which show a high tolerance for "deviations" from the standard life course model (such as cohabitation or childlessness). At the other end, in Southern and Eastern Europe the acceptance of "alternative" family behaviors is lower. 
Finally, Western Europe represents an intermediate group (Liefbroer and Merz 2009). Compared to more recent years, these cross-national differences were probably even larger in the past, when individuals who belong to the cohorts we examine were in their adulthood. The first time point at which we have some evidence is 1981, that is when the first wave of the European Values Studies offered, for the first time, comparative data on several countries (Halman et al. 2007). In that survey, for example, the percentage of respondents who declared divorce to be never justifiable was $24.1 \%$ in Italy against $9.5 \%$ in Sweden (EVS 2011).

In our analyses, we test the moderator role of the country context by clustering countries in four groups: Northern, Western, Southern and Eastern Europe. We are aware that country-grouping is a simplification that entails a certain loss of information. However, it represents a convenient and parsimonious way to test whether the association between nonstandardness of family histories and SWB of older people varies across macro contexts. As noticed above, the groups of countries we consider strongly differ in terms of norms related to demographic behaviors. Variations in demographic attitudes and behaviors across these groups of countries have also been widely documented within the framework of the SDT, and similar groupings as ours have been often employed (see e.g., Sobotka and Toulemon 2008; Lesthaeghe 2020). For example, Brzozowska (2021) use a similar grouping of countries based on SDT attitudinal and behavioral indices.

Changes in demographic behaviors that characterize the SDT started in the 1950s in Northern European countries and then spread to other regions, especially Western Europe (Lesthaeghe 2010). In the early phases of the SDT, differences across regions were striking (Lesthaeghe 2020). In the 1960s, for example, the percentage of children born outside marriage was about $10 \%$ in Northern and Western European countries, while it was extremely rare in Southern Europe (Sobotka and Toulemon 2008). Overall, Northern European countries showed the highest prevalence of non-standard demographic behaviors 
and the most tolerant attitudes towards "deviating" behaviors. Thus, we expect the association between non-standardness of family histories and older people's SWB to be the weakest in this group of countries. On the other extreme, we expect to find the Southern European group. The Western and Eastern European groups are expected to occupy intermediate positions in this ranking leaning, respectively, towards the pattern of results of Northern and Southern Europe.

In sum, we expect to find an overall negative association between the degree of nonstandardness of family histories and SWB at older ages. In addition, we expect this relationship to be stronger for lower educated individuals and in more "traditionalist" countries.

\section{Data and Methods}

\section{Sample and Variables}

Our analyses are based on data from the Survey of Health, Ageing and Retirement in Europe (SHARE). SHARE is a panel survey representative of the non-institutionalized population aged 50 and over in different European countries (Börsch-Supan et al. 2008). We constructed family trajectories using retrospective data collected in the seventh wave of SHARE (SHARE-7, 2017), where respondents were asked to provide detailed retrospective information in different life dimensions like fertility and partnership histories, as well as on early-life conditions. Our main outcome and control variables were also available in SHARE7. Only countries that participated in SHARE-7 are included in our analysis (Northern Europe: Denmark, Finland, Sweden; Western Europe: Austria, Belgium, France, Germany, Luxembourg, Switzerland; Southern Europe: Cyprus, Greece, Italy, Malta, Portugal, Spain; Eastern Europe: Bulgaria, Croatia, Czech Republic, Estonia, Hungary, Latvia, Lithuania, Poland, Romania, Slovakia, Slovenia). We restricted our sample to individuals aged 50 to 85 
years at the time of SHARE-7 and we reconstructed complete trajectories between ages 15 and 49 (both included, giving rise to 35 measurements on a yearly time scale). Hence, we analyze individuals born between 1932 and 1962. We dropped individuals born abroad and the few cases of individuals in homosexual couples. After applying the abovementioned selection criteria, the sample included 45,596 individuals. This reduced to 42,754 individuals (43.9\% women and $56.1 \%$ men) after deleting missing values in the variables of interest.

\section{Dependent Variable}

Our measure of SWB is the standard satisfaction with life measure from the question: "on a scale from 0 to 10 where 0 means completely dissatisfied and 10 means completely satisfied, how satisfied are you with your life?".

\section{Explanatory Variable}

The main independent variable in our regression analyses is the dissimilarity index, a measure of how different is the respondent's family trajectory with respect to those of the others in the same reference group. Details on the construction of this measure will be given in the next section.

\section{Control Variables}

We control for gender, age at the time of the survey and birth cohort (1932-1940; 1941-1950; 1951-1962). These three cohorts allowed to account for differences in the historical contexts experienced by individuals, while guaranteeing similar sample sizes in each group. In addition, we control for country of residence (Estonia is the reference category); education (ISCED educational level in three categories ("0-2" as the reference category; "3-4"; and "5- 
6 levels of ISCED") and percentage of years being employed between ages 15-49 in three categories ("75-100\%" - reference; "50-74\%"; and "less than 50\%").

As mentioned above, we also add a set of controls measuring early-life conditions to adjust for selection (on top of the control for education): living with biological parents at age 10 ("both biological parents" - reference; "only one biological parent"; "no biological parent"); occupation of main breadwinner at 10 ("managerial" - reference, "professional", "skilled non-manual"; "skilled manual"; "semi-skilled \& unskilled manual"; "other"; "without information"); self-defined health at childhood ("excellent" - reference; "very good"; "good"; "fair"; "poor"; "health varied a great deal"); overcrowding rate of the household at age 10, measured in terms of number of rooms per household member ("1 or less" - reference; "more than 1 to $1.5 "$ "; "more than 1.5 to 2"; "more than 2"; "without information"). Table 1 contains summary statistics on all variables used in the regression analyses.

< Table 1 about here >

\section{Methods}

We defined the possible states that shape the family trajectories according to individuals' union status (living without a partner=0U, living with a partner-married=1U, and living with a partner-cohabiting=2U) and the number of children at each time point of observation. To avoid states with small number of cases, we grouped together parities higher than the second, which produces four possible states: 0 children (0C); 1 child (1C); 2 children (2C) and 3 or more children $(3 \mathrm{OR}+\mathrm{C})$. The final combination of partnership and fertility information gave a total of 12 possible different states (0U0C; 0U1C; 0U2C; 0U3OR+C; 1U0C; 1U1C; 1U2C; 1U3OR+C; 2U0C; 2U1C; 2U2C; 2U3OR+C), measured yearly from age 15 to age 49 . 
Individual family histories have been compared based on Optimal Matching, a widely used approach in demographic research (Billari 2001; O'Flaherty et al. 2016). The purpose of using OM was to measure dissimilarities between trajectories by considering how much effort is required to transform one sequence into each of the others. Using this technique, the distances between individuals' sequences of family trajectories were calculated, generating a distance scores matrix. Following recent work (e.g., Comolli et al. 2021), we used the OM variant called dynamic Hamming matching (DHM; Lesnard 2010) to better account for timing of transitions. The algorithm calculates distances based on substitution costs (cost of substituting a state by another one) with time-dependent costs inversely proportional to observed transition frequencies from a state to another. Similar to Billari (2001), to account for differences in family histories by gender, country and birth cohort, we applied DHM within reference groups defined by these three dimensions. More specifically, for birth cohorts we considered the three groups already mentioned: 1932-1940; 1941-1950; 19511962. Our dissimilarity index is calculated as the mean of the distances resulting from DHM between each individual trajectory and all the trajectories within the reference group. Higher values of the index correspond to less standard family histories as compared to those of others with the same gender, country and birth cohort; thus, the dissimilarity index is a measure of non-standardness of family histories. The index was standardised within each reference group. Preliminary analyses showed a strongly non-linear relationship between the dissimilarity index and SWB. Thus, in all regression models we categorize this variable using quartiles (the reference category is the "first quartile", or more precisely the group of individuals with a value of the dissimilarity index smaller than the first quartile of its distribution).

In the final stage of the analysis, we estimated linear regression models to test the association between the quartiles of the dissimilarity index and life satisfaction. To examine 
the moderator role of gender, education and country we added interactions between these variables and the quartiles of the dissimilarity index. As anticipated above, in this step countries have been clustered in four groups: Northern Europe (Denmark, Finland, Sweden); Western Europe (Austria, Belgium, France, Germany, Luxembourg, Switzerland); Southern Europe (Cyprus, Greece, Italy, Malta, Portugal, Spain); Eastern Europe (Bulgaria, Croatia, Czech Republic, Estonia, Hungary, Latvia, Lithuania, Poland, Romania, Slovakia, Slovenia).

For the SA and DHM analyses we used the R package TraMineR (see Gabadinho et al. 2009), while the regression models having been estimated in the software STATA 16.

\section{Results}

First, we describe the four quartiles of the dissimilarity index according to the main family characteristics that define the family histories. Second, we show the results from the regression models about the association between life satisfaction at the time of the interview and the dissimilarity index quartiles controlling for socio-economic factors and early-life conditions. Third, we present results about the heterogeneity in the studied relationship. Finally, we summarize the results from a series of additional analyses and robustness checks.

\section{Family Profiles of the Quartiles of the Dissimilarity Index}

The four quartiles of the dissimilarity index present, as expected, different family features as can be seen according to summary statistics presented in Table 2. Given that the dissimilarity index measures and summarizes differences between family histories, the non-standardness of fertility and partnership behaviors increases from the first to the fourth quartile. Thus, the percentage of individuals who experienced union dissolution, cohabitation, re-partnership and extra-marital childbearing gradually rise from the first to the fourth quartile. We can notice that there is a feature that especially defines the fourth quartile and that barely any of the 
other groups displays: never had lived with a partner and the associated high level of childlessness. Among those who had children, the mean age at the first child is lowest in the fourth quartile of the dissimilarity index. In terms of number of children, while the first two quartiles are dominated by individuals who had 2 children, the other two quartiles show high percentages of individuals who had either less or more children than the modal value of 2 . Thereby, the fourth quartile, and to a lesser extent the third one, includes a varied set of nonstandard family experiences. Notice also that given the holistic nature of our approach, interrelated events (such as having children out-of-wedlock and early childbearing) are "clustered" together.

< Table 2 about here >

\section{Association Between SWB and Quartiles of the Dissimilarity Index}

Figure 1 displays the predicted values of life satisfaction by the quartiles of the dissimilarity index from a linear regression model (full regression estimates are available in Table S.1 in the Supplementary Materials). Life satisfaction tends to decrease as we move from the first to the last quartile. Individuals in all quartiles from the second to the fourth display statistically significantly lower life satisfaction as compared to individuals in the first quartile. The gap in life satisfaction is the strongest for the fourth against the first quartile ( 0.36 points). This is a practically significant effect if compared to the effect of other relevant predictors of life satisfaction, such as education (the coefficient of medium vs low education is 0.25 ; see Table S.1 in the Supplementary Materials). The gap in life satisfaction, instead, is minor and not statistically significant when comparing the two intermediate quartiles among themselves. 
Now let turn to the heterogeneity analyses. To ease interpretation of findings, Figures 2-4 present the results graphically in terms of marginal effects, comparing the average life satisfaction of individuals in the second, third and fourth quartile with that of individuals in the first one. Full regression estimates are available in Tables S.2-S.4 in the Supplementary Materials. Figure 2 shows that results by gender are very similar and differences in the marginal effects are not statistically significant (none of the interactions between the dissimilarity index quartiles with gender is statistically significant; Table S.2 in the Supplementary Materials). Thus, for both men and women non-standardness of family histories, in particular in the most "extreme" (fourth quartile of the dissimilarity index) are negatively associated with life satisfaction at older ages.

Figure 3 confirms our expectation about a stronger negative association between nonstandardness of family histories and SWB for lower educated individuals. More specifically, differences in marginal effects between the lowest educated group and the other two groups are statistically significant for the fourth quartile of the dissimilarity index. We tested these differences using Wald tests. Coherently with these tests, the interactions between the fourth quartile and both the medium and highest levels of education dummy variables are statistically significant (Table S.3 in the Supplementary Materials.). However, for all educational groups the gap in life satisfaction between the fourth and first quartile is statistically and substantively significant, although it is the highest for individuals with low education ( 0.43 points vs 0.33 points for individuals in the highest educational group).

Moving to the interactions between the dissimilarity index quartiles with country groups (Fig. 4), we observe that individuals in the fourth quartile show significantly lower life satisfaction as compared to the first one in all country groups. As expected, the association between non-standardness of family histories and SWB is the strongest in 
Southern Europe. More specifically, the marginal effect of the fourth quartile is significantly higher in Southern Europe ( 0.48 points vs about 0.30 points in the other regions; see also the statistically significant interaction between the fourth quartile of the dissimilarity index and the Southern Europe dummy variable in Table S.4). Instead, we do not find significant differences among the other groups of countries.

< Figures 2-4 about here >

\section{Robustness Checks and Additional Analyses}

We implemented a number of robustness checks and additional analyses. First, we added control variables measuring the experience of death of children or of the partner and the time since these events happened (Table S.5), as they may influence older people's wellbeing (Pudrovska 2009). Second, we considered alternative measures of psychological wellbeing: quality of life (measured by CASP-12) and number of depressive symptoms (measured using the EURO-D scale) (Tables S.6a-b). Note that in the latter case, a higher value of the outcome indicates worse wellbeing (i.e., a higher number of depressive symptoms). The aim of these analyses was to discard the possibility that our results are driven by the choice of a specific, although widely used in related demographic studies, measure of wellbeing.

Third, we addressed the issue of possible reverse causality. The negative association we find between non-standardness of family histories and SWB might be due to the fact that individuals' family histories might have been influenced by past (i.e., when fertility and partnership decisions were taken) levels of SWB. This possibility is reduced by controlling for education and early-life conditions, which includes a self-reported measure of childhood health. Also, related studies that used prospective data (Sironi et al. 2020), sibling fixedeffects (Barclay et al. 2016) or instrumental variables (IV) techniques found evidence of 
long-term effects of family histories on wellbeing, health and mortality at older ages. Differently from studies on a specific aspect of family histories (e.g., number of children, see e.g., van den Broek and Tosi 2020) adopting an IV approach in our case is not feasible. However, we implemented the approach proposed by Lewbel (2012), who showed that regression model parameters can be identified in the presence of heteroscedasticity, thus adjusting for possible endogeneity issues. Results, obtained with the STATA package ivreg $2 h$ (Baum and Schaffer 2012), are shown in Table S.7.

Finally, we have included several specific measures of fertility and partnership histories as independent variables (Table S.8). The aim here is to check whether the association between the dissimilarity index quartiles and SWB is driven by specific aspects of the family life course: age at first time living with partner; having experienced a divorce/separation; having experienced a cohabitation; having experienced a re-partnering; age at first birth; total number of children at age 49; having given birth to any child out of wedlock.

Results from all robustness checks confirmed the findings reported above for the main analyses. In all cases, in fact individuals who experienced the more standard family histories (first quartile of the dissimilarity index) shows the highest level of wellbeing (i.e., higher life satisfaction, higher quality of life, lower number of depressive symptoms). There is one exception: in the case of the instrumental variable regression (Table S.7), although all three upper quartiles of the dissimilarity index maintain a negative coefficient, we find a statistically significant effect only for the fourth quartile.

It is worth describing in more detail the final analysis mentioned above. Results show that adding specific variables related to family histories explains parts of the effects of the dissimilarity index quartiles (Table S.8), but these effects are not completely canceled. The biggest change in the coefficients of the dissimilarity index quartiles is produced in model 7 
where we account for whether the respondent had children born out of wedlock. In all models the coefficient for the fourth quartile remains statistically and substantially significant, even in the final model where all the specific variables are included together (model 8). This confirms that our holistic dissimilarity index based on Sequence Analysis and Optimal Matching is able to account for complexities in fertility and partnership histories not easily summarized by specific aspects of these histories.

\section{Conclusion}

Adopting a life course perspective, we examined the association between the degree of nonstandardness of family histories and subjective wellbeing (SWB) of older people in Europe. We also assessed the heterogeneity in this relationship by gender, education and country groups. Our measure of non-standardness of family life courses was constructed by applying sequence analysis and optimal matching to retrospective data from the seventh wave of the Survey of Health Ageing and Retirement (SHARE) in Europe. We calculated distances between each individual family trajectory and all the others within the same group defined by gender, birth cohort and country. This dissimilarity index was categorized in quartiles and constituted our explanatory variable in regression analyses where the main outcome variable was life satisfaction.

Based on theoretical insights from the life course perspective and the institutionalization framework related to the existence of social norms that influence demographic behaviors (Liefbroer and Billari 2010), we hypothesized that those individuals who experienced non-standard family histories accumulated stress and negative feelings throughout their life course which might have reflected in negative long-term influence on their SWB at older ages. This assumption was confirmed for both men and women, for all educational and country groups: the more the individuals' family history deviated from those 
experienced by others, the lower their SWB tended to be in later life. The "disadvantage" in terms of SWB was particularly significant from a substantive point of view when comparing individuals in the fourth versus those in the first quartile of the dissimilarity index.

Our results were robust to a series of checks related to, for example, the inclusion of additional control variables or the use of different measures of wellbeing. We also showed that adding specific variables related to family histories reduced but did not eliminate the effects of the dissimilarity index quartiles, thus confirming the utility of holistic approaches, also adopted in previous related studies on the association between family histories and health or wellbeing (Barban 2013; Comolli et al. 2021; Kravdal et al. 2012; Lacey et al. 2016; O'Flaherty et al. 2016), to account for complexities in fertility and partnership histories not straightforwardly summarized by specific aspects of family trajectories.

Heterogeneity analyses confirmed our expectation of a stronger negative association between non-standardness of family histories and SWB for lower educated individuals and people from Southern Europe, in line with the idea that the sanctions connected to nonstandard demographic behaviors have implications that may be different according to individual resources and the normative and institutional context (Liefbroer and Billari 2010; Thoits 1995; Zoutewelle-Terovan and Liefbroer 2018). Instead, women and men who experienced non-standard family life courses showed similarly lower levels of SWB compared to their counterparts with more standard fertility and partnership histories. This finding is consistent with research showing similar associations by gender between wellbeing and non-standard demographic behaviors (Kalmijn 2010; Koropeckyj-Cox et al. 2007; Soons et al. 2009; Zoutewelle-Terovan and Liefbroer 2018).

The current study adds to the growing body of research on the long-term consequences of demographic behaviors on later life health and wellbeing (Arpino et al. 2018b; Grundy and Tomassini 2010; Grundy and Holt 2000; Hank 2010; Kravdal et al. 2012; 
Quashie et al. 2021; Sironi 2019; Sironi et al. 2020). In particular, our findings align with earlier studies documenting lower wellbeing among individuals who experienced nonstandard demographic behaviors. While most of these studies have focused on the general population (e.g., Verbakel 2012) and/or on specific behaviors, such as cohabitation (e.g., Soons and Kalmijn 2009), the current study adds a holistic approach applied to fertility and partnership histories and their consequences on SWB at older ages.

This research is not without limitations, which ought to provide direction for future research. As all analyses relying on SHARE and similar data, our sample is selected because we can only observe individuals who survived till age 50 and more. This likely implies underestimating the effect of non-standardness of family life course because individuals who suffered the most from the sanctions implied by the adoption of deviating family behaviors may have died earlier. The relationship between non-standardness of family histories and mortality is an interesting avenue for future research. As mentioned in the introduction, selection effects can be due also to the impact of early life course disadvantage on subsequent family trajectories (Arpino et al. 2018b; Perelli-Harris et al. 2019; Pudrovska and Anikputa, 2012). Similar to recent studies on family histories and health or wellbeing (Comolli et al. 2021; O'Flaherty et al. 2016), we relied on retrospectively measured information on early life conditions to address, at least in part, this issue. However, retrospective measures of early life course conditions could be affected by recall bias. Havari and Mazzonna (2015) reported a high degree of internal and external consistency of the SHARELIFE measures of childhood health and socio-economic status we use, suggesting that overall individuals seem to remember fairly well their childhood. Nonetheless, future studies could rely on prospective data to avoid recall bias and also to better control for reverse causality.

Previous research has demonstrated that wellbeing penalizations of non-standard demographic behaviors tend to weaken as these behaviors become more common. For 
example, the negative effect of cohabitation and divorce versus being married has reduced with the increased prevalence of cohabitation (Pirani and Vignoli 2016; Soons and Kalmijn 2009) and divorce (Kalmijn 2010; Verbakel 2012), respectively. Thus, given a certain degree of increased diversification in family life courses in the past century (Van Winkle 2018), weaker associations between non-standardness of family histories and older people's wellbeing may be expected in the future, as compared to those found in the current study. Policy interventions can also be implemented to mitigate the consequences of non-standard demographic behaviors. These include, for example, laws granting similar rights (e.g., tax benefits) to married and cohabiting couples or to children irrespectively of the marital status of their parents. Also, educational interventions (e.g., in schools or through media campaigns) to spread values of tolerance towards behaviors that differ from traditional ones may help in lowering the social sanctions attached to non-standard behaviors.

Ultimately, our results bring new evidence on the long-lasting effects of family behaviors on wellbeing at older ages and, in particular, they suggest that the degree of nonstandardness of family histories is negatively associated with wellbeing in later life, especially for lower educated individuals and those in more traditionalist contexts. 


\section{References}

Aassve, A., Goisis, A., \& Sironi, M. (2012). Happiness and childbearing across Europe. Social indicators research, 108(1), 65-86.

Abbott, A. (1995). Sequence Analysis: New Methods for Old Ideas. Annual Review of Sociology, 21, 93-113.

Abbott, A., \& Tsay. A. (2000). Sequence Analysis and Optimal Matching Methods in Sociology. Sociological Methods \& Research, 29, 3-33.

Arpino, B., Bordone, V., \& Balbo, N. (2018a) Grandparenting, education and subjective wellbeing of older Europeans. European Journal of Ageing, 15(3), 251-263.

Arpino, B., Gumà, J., \& Julià, A. (2018b). Early-life conditions and health at older ages: The mediating role of educational attainment, family and employment trajectories. PloS one, 13(4), $\mathrm{e} 0195320$.

Barclay, K., Keenan, K., Grundy, E., Kolk, M., \& Myrskylä, M. (2016). Reproductive history and post-reproductive mortality: A sibling comparison analysis using Swedish register data. Social Science \& Medicine, 155, 82-92.

Barban, N. (2013). Family trajectories and health: a life course perspective. European Journal of Population, 29(4), 357-385.

Balbo, N., \& Arpino, B. (2016). The role of family orientations in shaping the effect of fertility on subjective well-being: a propensity score matching analysis. Demography, 53(4), 955-978.

Barker, D. (2004). Developmental origins of adult health and disease. Journal of epidemiology and community health, 58(2), 114.

Baum, C. F., \& Schaffer, M. E. (2012). ivreg2h: Stata module to perform instrumental variables estimation using heteroskedasticity-based instruments. Retrieved on February 10, 2016, from http://ideas. repec.org/c/boc/bocode/s457555.html 
Be, D., Whisman, M. A., \& Uebelacker, L. A. (2013). Prospective associations between marital adjustment and life satisfaction. Personal Relationships, 20(4), 728-739.

Becker, C., Kirchmaier, I., \& Trautmann, S. T. (2019). Marriage, parenthood and social network: Subjective well-being and mental health in old age. PloS one, 14(7), e0218704.

Ben-Shlomo, Y., \& Kuh, D. (2002). A life course approach to chronic disease epidemiology: Conceptual models, empirical challenges and interdisciplinary perspectives. International Journal of Epidemiology, 31, 285-293.

Billari, F. C. (2009). The happiness commonality: Fertility decision in low-fertility settings. In UNECE (Ed.), How generations and gender shape demographic change (pp. 738). New York/Geneva: United Nations.

Billari, F. C. (2001). Sequence analysis in demographic research. Canadian Studies in Population, 28(2), 439-458.

Billari, F. C., \& Liefbroer, A. C. (2007). Should I Stay or Should I Go? The Impact of Age Norms on Leaving Home. Demography, 44 (1), 181-198.

Börsch-Supan, A., Brugiavini, A., Jürges, H., Kapteyn, A., Mackenbach, J., Siegrist, J., \& Weber, G. (2008). First results from the Survey of Health, Ageing and Retirement in Europe (2004-2007). Starting the longitudinal dimension. Mannheim: MEA.

Brown, S. L. (2000). The effect of union type on psychological well-being: Depression among cohabitors versus marrieds. Journal of health and social behavior, 241-255.

Brzozowska, Z. (2021). Attitudinal and behavioural indices of the second demographic transition: Evidence from the last three decades in Europe. Demographic Research, $44,1115-1132$.

Carr, D., \& Utz, R. L. (2020). Families in later life: A decade in review. Journal of Marriage and Family, 82(1), 346-363. 
Cherlin, A. J. (2004). The deinstitutionalization of American marriage. Journal of marriage and family, 66(4), 848-861.

Comolli, C. L., Bernardi, L. \& Voorpostel, M. (2021) Joint Family and Work Trajectories and Multidimensional Wellbeing. European Journal of Population. On-line first. https://doi.org/10.1007/s10680-021-09583-3

Conzo, P., Fuochi, G., \& Mencarini, L. (2017). Fertility and life satisfaction in rural Ethiopia. Demography, 54(4), 1331-1351.

Cunningham, A., \& Knoester, C. (2010). The Psychological Well-Being of Single Parents. Focus on Single-Parent Families: Past, Present, and Future.

Deaton, A., \& Stone, A. A. (2014). Evaluative and hedonic wellbeing among those with and without children at home. Proceedings of the National Academy of Sciences, 111(4), $1328-1333$.

Espenshade T.J. (1985). Marriage trends in America: Estimates, implications, and underlying causes. Population and Development Review, 11, pp. 193-245.

EVS (2011). European Values Study 1981, 1st wave, Integrated Dataset. GESIS Data Archive, Cologne, Germany, ZA4436 Data File Version 3.0.0 (2011-11-20), doi:10.4232/1.10791.

Gabadinho, A., Ritschard, G., Studer, M., \& Müller, N. S. (2009). Mining sequence data in R with the TraMineR package: A user's guide. Geneva: Department of Econometrics and Laboratory of Demography, University of Geneva.

Grundy, E., \& Holt, G. (2000). Adult life experiences and health in early old age in Great Britain. Social science \& medicine, 51(7), 1061-1074.

Grundy, E., \& Kravdal, Ø. (2010). Fertility history and cause-specific mortality: a registerbased analysis of complete cohorts of Norwegian women and men. Social science \& medicine, 70(11), 1847-1857. 
Grundy, E. M., \& Tomassini, C. (2010). Marital history, health and mortality among older men and women in England and Wales. BMC public health, 10(1), 1-14.

Gumà, J., \& Fernández-Carro. C. (2021). Life goes on: The influence of the perceived quality of social relations on older women's mental health after the loss of a partner in Europe. Aging \& Mental Health, 25(1), 53-60

Halman, L., Inglehart, R. L., Díez-Medrano, J., Luijkx, R., Moreno, A., \& Basáñez, M. (Eds.). (2007). Changing values and beliefs in 85 countries: Trends from the values surveys from 1981 to 2004 . Brill.

Hayward, M. D., \& Gorman, B. K. (2004). The long arm of childhood: The influence of early-life social conditions on men's mortality. Demography, 41(1), 87-107.

Hank, K. (2010). Childbearing history, later-life health, and mortality in Germany. Population Studies, 64(3), 275-291.

Hank, K., \& Wagner, M. (2013). Parenthood, marital status, and well-being in later life: evidence from SHARE. Social Indicators Research, 114, 639-653.

Havari, E., \& Mazzonna, F. (2015). Can we trust older people's statements on their childhood circumstances? Evidence from SHARELIFE. European Journal of Population, 31(3), 233-257.

Henretta, J. C. (2007). Early childbearing, marital status and women's health and mortality after age 50. Journal of Health and Social Behavior, 48, 254-266.

Hofäcker, D., \& Chaloupková, J. (2014). Patterns of Family Life Courses in Europe between Standardisation and Diversity A Cross-national Comparison of Family Trajectories and Life Course Norms in European Countries. Comparative Population Studies, 39(3), 559-586. 
Huijts, T., Kraaykamp, G., \& Subramanian, S. V. (2013). Childlessness and psychological well-being in context: A multilevel study on 24 European countries. European Sociological Review, 29(1), 32-47.

Kalmijn, M. (2010). Country Differences in the Effects of Divorce on Well-Being: The Role of Norms, Support, and Selectivity. European Sociological Review, 26(4), 475-490.

Kim, H. K., \& McKenry, P. C. (2002). The relationship between marriage and psychological well-being: A longitudinal analysis. Journal of family Issues, 23(8), 885-911.

Kim, S., Thibodeau, R., \& Jorgensen, R. S. (2011). Shame, guilt, and depressive symptoms: a meta-analytic review. Psychological bulletin, 137(1), 68.

Kohler, H. P., \& Mencarini, L. (2016). The parenthood happiness puzzle: An introduction to special issue. European Journal of Population, 32(3), 327-338.

Koropeckyj-Cox, T., Pienta, A. M., \& Brown, T. H. (2007). Women of the 1950s and the "normative" life course: The implications of childlessness, fertility timing, and marital status for psychological well-being in late midlife. The International Journal of Aging and Human Development, 64(4), 299-330.

Kravdal, Ø., Grundy, E., Lyngstad, T., \& Wiik, K. (2012). Family life history and late midlife mortality in Norway. Population and Development Review, 38, 237-257.

Kuh, D., Hardy, R., Gale, C., Elliott, J., Ben-Shlomo, Y., Cooper, R., \& the HALCyon Study Team (2018). Healthy ageing across the life course. In A. Walker (Ed.) The New Dynamics of Ageing (Vol. 1, pp. 59-79). Policy Press: UK.

Jensen, R. E., \& Bute, J. J. (2010). Fertility-related perceptions and behaviors among lowincome women: Injunctive norms, sanctions, and the assumption of choice. Qualitative Health Research, 20(11), 1573-1584.

Inglehart, R., \& Baker, W. E. (2000). Modernization, cultural change, and the persistence of traditional values. American Sociological Review, 65, 19-51. 
Lacey, R., Stafford, M., Sacker, A., \& McMunn, A. (2016). Work-family life courses and subjective wellbeing in the MRC National Survey of Health and Development (the 1946 British birth cohort study). Journal of population ageing, 9(1-2), 69-89.

Lesnard, L. (2010). Setting cost in optimal matching to uncover contemporaneous sociotemporal patterns. Sociological methods \& research, 38(3), 389-419.

Lesthaeghe, R. (2020). The second demographic transition, 1986-2020: sub-replacement fertility and rising cohabitation—a global update. Genus, 76(1), 1-38.

Lewbel, A. (2012). Using heteroscedasticity to identify and estimate mismeasured and endogenous regressor models. Journal of Business \& Economic Statistics, 30(1), 6780.

Liefbroer, A. C., \& Billari, F. C. (2010). Bringing norms back in: A theoretical and empirical discussion of their importance for understanding demographic behaviour. Population, space and place, 16(4), 287-305.

Liefbroer, A., \& Merz, E.-M. (2009). Report on analysis of ESS data on cross-national differences in perceived norms concerning fertility-related behaviour. REPRO (Reproductive Decision-Making in a Macro-Micro Perspective) deliverables 16 (6). Vienna Institute of Demography: Vienna.

Lindenberg, S. (2001). Intrinsic motivation in a new light. Kyklos, 54(2-3), 317-342.

Macmillan, R., \& Copher, R. (2005). Families in the life course: Interdependency of roles, role configurations and pathways. Journal of Marriage and Family, 67, 858-879.

Margolis, R., \& Myrskylä, M. (2011). A global perspective on happiness and fertility. Population and development review, 37(1), 29-56.

McFarland, M. J., Hayward, M. D., \& Brown, D. (2013). I've got you under my skin: marital biography and biological risk. Journal of Marriage and Family, 75(2), 363-380.

Merton, R. K. (1968). Social Theory and Social Structure. Free Press: New York. 
Mikucka, M. (2016). The life satisfaction advantage of being married and gender specialization. Journal of Marriage and Family, 78(3), 759-779.

Montgomery, M. R., \& Casterline, J. B. (1996). Social learning, social influence and new models of fertility. In J. B. Casterline, R. D. Lee, K. A. Foote (Eds.), Fertility in the United States: New Patterns, New Theories (pp. 151-175), Supplement to Volume 22 of Population and Development Review.

Myrskylä, M., \& Margolis, R. (2014). Happiness: Before and after the kids. Demography, 51(5), 1843-1866.

Nomaguchi, K. M., \& Milkie, M. (2003). Costs and rewards of children: The effects of becoming a parent on adults' lives. Journal of Marriage and Family, 66, 413-430.

O'Flaherty, M., Baxter, J., Haynes, M., \& Turrell, G. (2016). The family life course and health: Partnership, fertility histories, and later-life physical health trajectories in Australia. Demography, 53(3), 777-804.

Perelli-Harris, B., Hoherz, S., Lappegård, T., \& Evans, A. (2019). Mind the "happiness" gap: The relationship between cohabitation, marriage, and subjective well-being in the United Kingdom, Australia, Germany, and Norway. Demography, 56(4), 1219-1246.

Pirani, E., \& Vignoli, D. (2016). Changes in the satisfaction of cohabitors relative to spouses over time. Journal of Marriage and Family, 78(3), 598-609.

Posner, R. A., \& Rasmusen, E. B. (1999). Creating and enforcing norms, with special reference to sanctions. International Review of law and economics, 19(3), 369-382.

Pudrovska, T. (2009). Parenthood, stress, and mental health in late midlife and early old age. The International Journal of Aging and Human Development, 68(2), 127-147.

Pudrovska, T., \& Anikputa, B. (2012). The role of early-life socioeconomic status in breast cancer incidence and mortality: unraveling life course mechanisms. Journal of aging and health, 24(2), 323-344. 
Pudrovska, T., \& Anikputa, B. (2014). Early-life socioeconomic status and mortality in later life: An integration of four life-course mechanisms. Journals of Gerontology Series B: Psychological Sciences and Social Sciences, 69(3), 451-460.

Quashie N., Arpino B., Antczak R. \& Mair C. (2021). Childlessness and Health among Older Adults: Variation across 5 Outcomes and 20 Countries. The Journal of Gerontology: Series B, 76(2), 348-359.

Read, S., \& Grundy, E. (2011). Fertility history and quality of life in older women and men. Ageing \& Society, 31(1), 125-145.

Reczek, C., Pudrovska, T., Carr, D., Thomeer, M. B., \& Umberson, D. (2016). Marital histories and heavy alcohol use among older adults. Journal of health and social behavior, 57(1), 77-96.

Rijken, A. J., \& Liefbroer, A. C. (2016). Differences in family norms for men and women across Europe. Journal of Marriage and Family, 78(4), 1097-1113.

Rijken, A. J., \& Merz, E. M. (2014). Double standards: Differences in norms on voluntary childlessness for men and women. European sociological review, 30(4), 470-482.

Sabbath, E. L., Guevara, I. M., Glymour, M. M., \& Berkman, L. F. (2015). Use of life course work-family profiles to predict mortality risk among US women. American Journal of Public Health, 105, e96-e102

Settersten, R. A. Jr. (2003). Normative structuring of the life course. In J.T. Mortimer, M. J. Shanahan (Eds), Handbook of the Life Course (pp. 81-98). Kluwer Academic Press: New York.

Settersten, R.A. Jr., \& Hagestad, G. O. (1996). What's the latest? Cultural age deadlines for family transitions. The Gerontologist, 36, 178-188.

Sironi, M. (2019). Fertility histories and chronic conditions later in life in Europe. European journal of ageing, 16(3), 259-272. 
Sironi, M., Ploubidis, G. B., \& Grundy, E. M. (2020). Fertility history and biomarkers using prospective data: Evidence from the 1958 national child development study. Demography, 57(2), 529-558.

Sobotka, T., \& Toulemon, L. (2008). Overview Chapter 4: Changing family and partnership behaviour: Common trends and persistent diversity across Europe. Demographic research, 19, 85-138.

Soons, J. P., \& Kalmijn, M. (2009). Is marriage more than cohabitation? Well-being differences in 30 European countries. Journal of Marriage and Family, 71(5), 11411157.

Soons, J. P. M., Liefbroer, A. C., \& Kalmijn, M. (2009). The Long-Term Consequences of Relationship Formation for Subjective Well-Being. Journal of Marriage and Family, $71,1254-1270$.

Solé-Auró, A., \& Cortina, C. (2019). Exploring the role of family ties on life satisfaction in later life in Europe. Journal of Family Research, 31(2), 180-198.

Stavrova, O. (2014). Fitting in and getting happy: How conformity to societal norms affects subjective wellbeing. Frankfurt, Germany: Campus Publishers.

Stavrova, O., \& Fetchenhauer, D. (2015). Single parents, unhappy parents? Parenthood, partnership, and the cultural normative context. Journal of Cross-Cultural Psychology, 46(1), 134-149.

Surkyn, J., \& Lesthaeghe, R. (2004). Value Orientations and the Second Demographic Transition (SDT) in Northern, Western and Southern Europe. An Update. Demographic Research, 3, 45-86.

Thoits, P. A. (1995). Stress, coping, and social support processes: Where are we? What next?. Journal of health and social behavior, 53-79. 
Thornton A, \& Young-DeMarco L. (2001). Four decades of trends in attitudes toward family issues in the United States: the 1960s through the 1990s. Journal of Marriage and Family, 63, 1009-1037.

Umberson, D., \& Gove, W. R. (1989). Parenthood and psychological well-being: Theory, measurement, and stage in the family life course. Journal of family issues, 10(4), 440462.

Umberson, D., Pudrovska, T., \& Reczek, C. (2010). Parenthood, Childlessness, and WellBeing: A Life Course Perspective. Journal of Marriage and Family, 72, 612-629.

Umberson, D., \& Thomeer, M. B. (2020). Family matters: Research on family ties and health, 2010 to 2020. Journal of Marriage and Family, 82(1), 404-419.

van den Broek, T., \& Tosi, M. (2020). The more the merrier? The causal effect of high fertility on later-life loneliness in Eastern Europe. Social Indicators Research, 1-16.

van de Kaa, D. J. (1994). The second demographic transition revisited: Theories and expectations. In G. Beets, H. van Den Brekel, R. L. Cliquet, G. Dooghe und J. de Jong Gierveld (Eds.). Population and family in the Low Countries 1993: Late fertility and other current issues (pp. 81-126). Berwyn, Pennsylvania, Amsterdam: Swets and Zeitlinger.

Van Winkle, Z. (2018). Family trajectories across time and space: Increasing complexity in family life courses in Europe?. Demography, 55(1), 135-164.

Verbakel, E. (2012). Subjective well-being by partnership status and its dependence on the normative climate. European Journal of Population, 28(2), 205-232.

Waite, L. J., \& Gallagher, M. (2000). The case for marriage: Why married people are happier, healthier, and better off financially. New York: Doubleday.

Wright, M. R., \& Brown, S. L. (2017). Psychological well-being among older adults: The role of partnership status. Journal of Marriage and Family, 79(3), 833-849. 
Zhang, Z., \& Hayward, M. D. (2001). Childlessness and the psychological well-being of older persons. The Journals of Gerontology Series B: Psychological Sciences and Social Sciences, 56(5), S311-S320.

Zimmermann, A. C., \& Easterlin, R. A. (2006). Happily ever after? Cohabitation, marriage, divorce, and happiness in Germany. Population and development review, 511-528.

Zoutewelle-Terovan, M., \& Liefbroer, A. C. (2018). Swimming against the stream: Nonnormative family transitions and loneliness in later life across 12 nations. The Gerontologist, 58(6), 1096-1108. 


\section{Tables and Figures}

Table 1. Summary statistics: means $(M)$ or percentages and number of cases $(N)$

\begin{tabular}{|c|c|c|c|}
\hline Variable & Mean or $\%(\mathrm{~N})$ & Variable & Mean or $\%(\mathrm{~N})$ \\
\hline Life Satisfaction (M) & 7.5 & Age (M) & 67.6 \\
\hline Dissimilarity index & & Cohort & \\
\hline Quartile 1 & $25.0(11,400)$ & 1932-1940 & $17.2(7,837)$ \\
\hline Quartile 2 & $25.0(11,398)$ & $1941-1950$ & $34.3(15,636)$ \\
\hline Quartile 3 & $25.0(11,399)$ & $1951-1962$ & $48.5(22,123)$ \\
\hline Quartile 4 & $25.0(11,399)$ & $\%$ of years being employed & \\
\hline Gender & & $75 \%-100 \%$ & $54.7(24,697)$ \\
\hline Female & $56.1(25,568)$ & $50 \%-74 \%$ & $26.5(11,938)$ \\
\hline Male & $43.9(20,028)$ & Less than $50 \%$ & $18.8(8,477)$ \\
\hline Country & & Education & \\
\hline Austria & $4.7(2,128)$ & ISCED $<3$ & $34.8(15,855)$ \\
\hline Germany & $5.1(2,319)$ & ISCED 3 or 4 & $44.2(20,139)$ \\
\hline Sweden & $3.7(1,706)$ & ISCED $>4$ & $21.0(9,602)$ \\
\hline Spain & $5.8(2,623)$ & Living with parents at age 10 & \\
\hline Italy & $5.4(2,248)$ & Both biological & $88.2(40,196)$ \\
\hline France & $3.4(1,575)$ & Only one biological parent & $9.4(4,271)$ \\
\hline Denmark & $3.3(1,493)$ & None biological parent & $2.4(1,096)$ \\
\hline Greece & $2.0(903)$ & No information & $0.1(33)$ \\
\hline Switzerland & $2.6(1,199)$ & \multicolumn{2}{|c|}{ Occupation of main breadwinner at age 10} \\
\hline Belgium & $5.1(2,343)$ & $\begin{array}{l}\text { Managerial, professional, } \\
\text { skilled non-manual }\end{array}$ & $27.8(12,051)$ \\
\hline Czech Republic & $6.1(2,764)$ & Skilled manual & $18.0(7,772)$ \\
\hline Poland & $5.9(2,674)$ & Semi-skilled/unskilled & $28.2(12,182)$ \\
\hline Luxembourg & $1.6(714)$ & Other & $7.2(3,105)$ \\
\hline Hungary & $3.0(1,376)$ & No information & $18.8(8,115)$ \\
\hline Portugal & $0.9(412)$ & \multicolumn{2}{|c|}{ Overcrowding rate of the household at age 10} \\
\hline Slovenia & $6.2(2,842)$ & 1 or less & $21.2(9,677)$ \\
\hline Estonia & $6.9(3,162)$ & More than 1 to 1.5 & $22.5(10,268)$ \\
\hline Croatia & $3.7(1,709)$ & More than 1.5 to 2 & $22.6(10,313)$ \\
\hline Lithuania & $3.2(1,475)$ & More than 2 & $29.5(13,433)$ \\
\hline Bulgaria & $3.6(1,651)$ & No information & $4.2(1,905)$ \\
\hline Cyprus & $2.1(963)$ & Self-defined health at childhood & \\
\hline Finland & $3.5(1,610)$ & Excellent & $31.3(14,271)$ \\
\hline Latvia & $2.3(1,069)$ & Very good & $31.3(14,256)$ \\
\hline Malta & $2.4(1,104)$ & Good & $26.9(12,281)$ \\
\hline Romania & $3.8(1,727)$ & Fair & $7.7(3,508)$ \\
\hline \multirow[t]{2}{*}{ Slovakia } & $3.4(1,573)$ & Poor & $2.6(1,163)$ \\
\hline & & Health varied a great deal & $0.2(103)$ \\
\hline
\end{tabular}


Table 2. Family characteristics by the quartiles of the standardized dissimilarity index

\begin{tabular}{|c|c|c|c|c|c|}
\hline \multirow{2}{*}{ Variables } & \multicolumn{4}{|c|}{ Quartiles } & \multirow[b]{2}{*}{ Total } \\
\hline & 1 & 2 & 3 & 4 & \\
\hline \multicolumn{6}{|l|}{$1^{\text {st }}$ time living with partner } \\
\hline Median age & 24 & 23 & 23 & 22 & 23 \\
\hline Never $(\%)$ & 0 & 0 & 0 & 19 & 5 \\
\hline Experienced a union dissolution (\%) & 8 & 14 & 22 & 28 & 18 \\
\hline Experienced a cohabitation $(\%)$ & 1 & 2 & 5 & 18 & 7 \\
\hline Experienced re-partnering (\%) & 5 & 10 & 14 & 16 & 11 \\
\hline $1^{\text {st }}$ child (Median age) & 26 & 24 & 25 & 23 & 25 \\
\hline \multicolumn{6}{|l|}{ Number of children (at age 49) } \\
\hline 0 & 0 & 0 & 5 & 39 & 11 \\
\hline 1 & 0 & 6 & 37 & 29 & 18 \\
\hline 2 & 90 & 61 & 18 & 10 & 45 \\
\hline 3 or + & 10 & 32 & 41 & 23 & 26 \\
\hline Had children out of wedlock (\%) & 4 & 14 & 22 & 35 & 19 \\
\hline
\end{tabular}


Figure 1. Predicted life satisfaction by the dissimilarity index quartiles

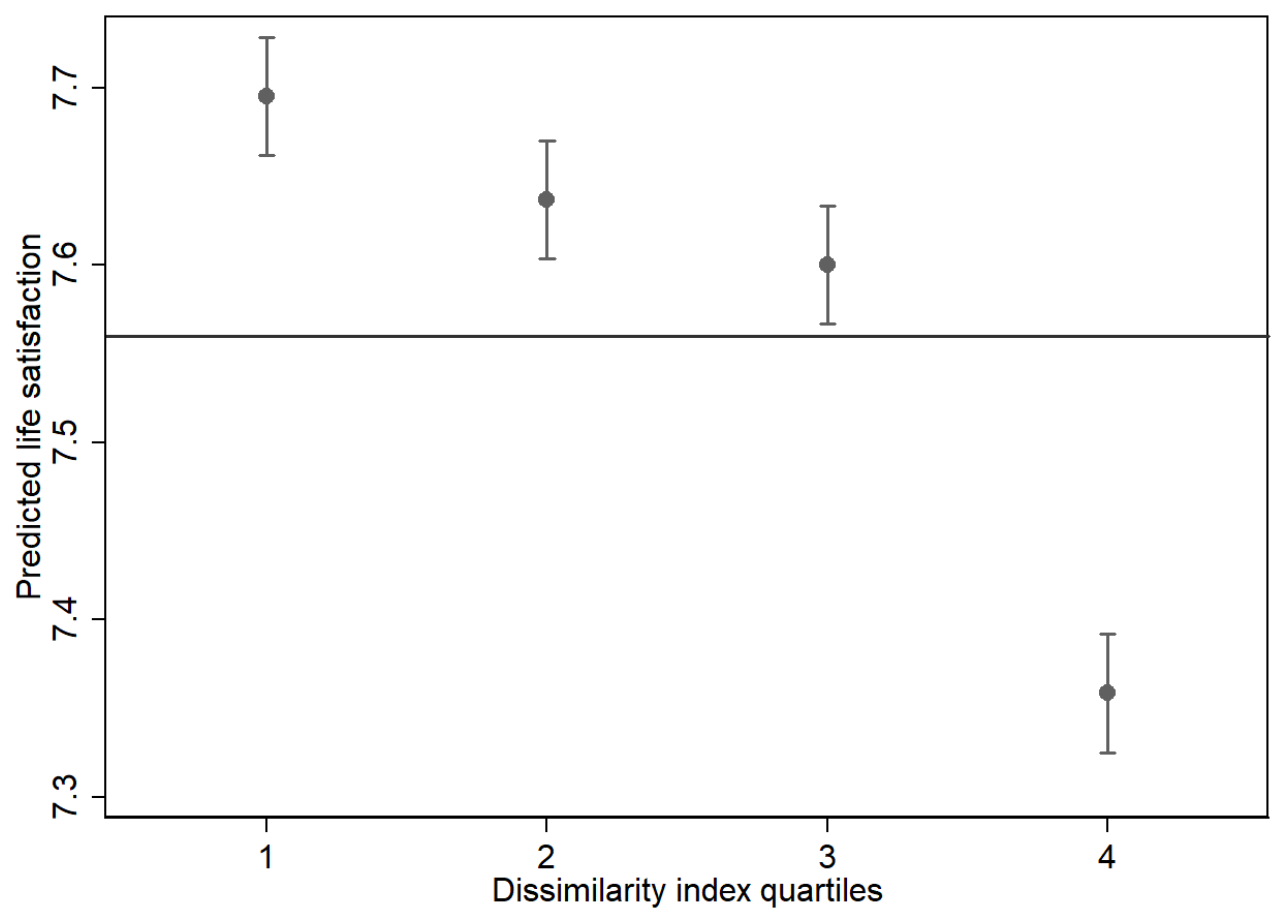

Note: The graph plots predicted values of life satisfaction obtained from model with all control variables included (estimated coefficients are reported in Table S.1 of the Supplementary Materials). The horizontal line corresponds to the overall average level of life satisfaction. 
Figure 2. Marginal effects (ME) on life satisfaction of the dissimilarity index (DI) quartiles (compared to the first quartile) by gender with $95 \%$ confidence intervals

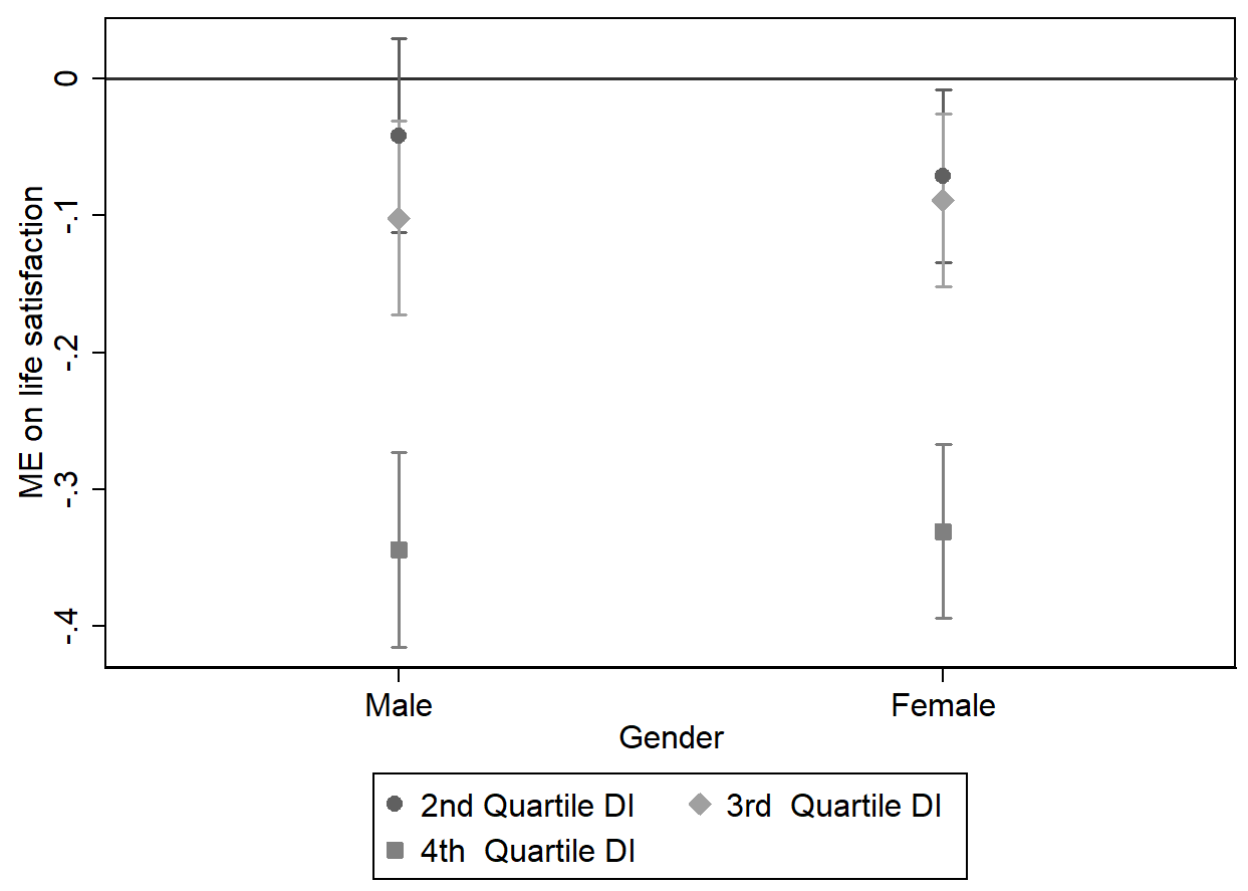

Note: The graph plots the marginal effect of the dissimilarity index quartiles (compared to the first one) on life satisfactions by gender obtained from a model that includes interactions with gender and where all control variables are included (estimated coefficients are reported in Table S.2 of the Supplementary Materials). 
Figure 3. Marginal effects (ME) on life satisfaction of the dissimilarity index (DI) quartiles (compared to the first quartile) by education with $95 \%$ confidence intervals

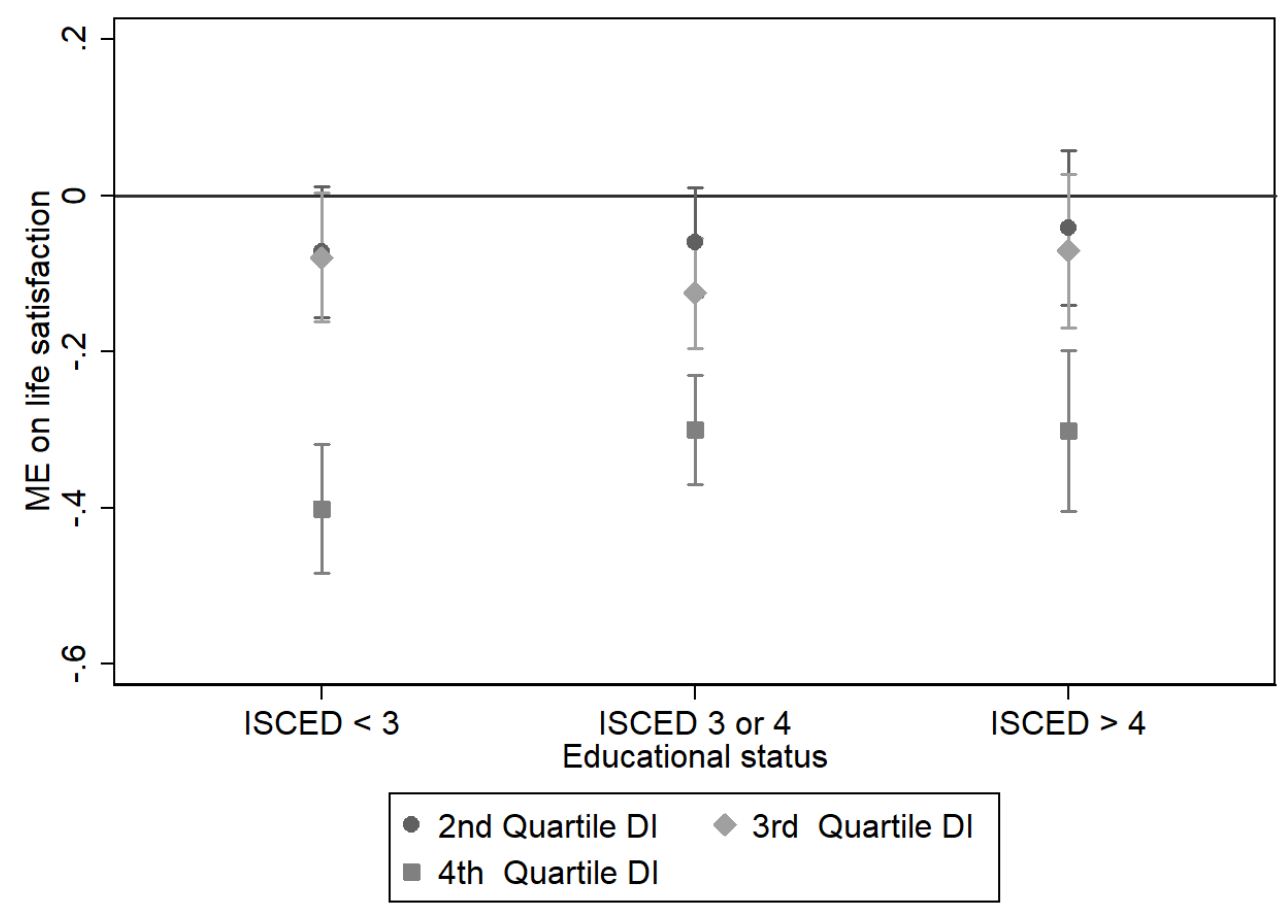

Note: The graph plots the marginal effect of the dissimilarity index quartiles (compared to the first one) on life satisfactions by education obtained from a model that includes interactions with education and where all control variables are included (estimated coefficients are reported in Table S.3 of the Supplementary Materials). 
Figure 4. Marginal effects (ME) on life satisfaction of the dissimilarity index (DI) quartiles (compared to the first quartile) by country groups $-95 \%$ confidence intervals

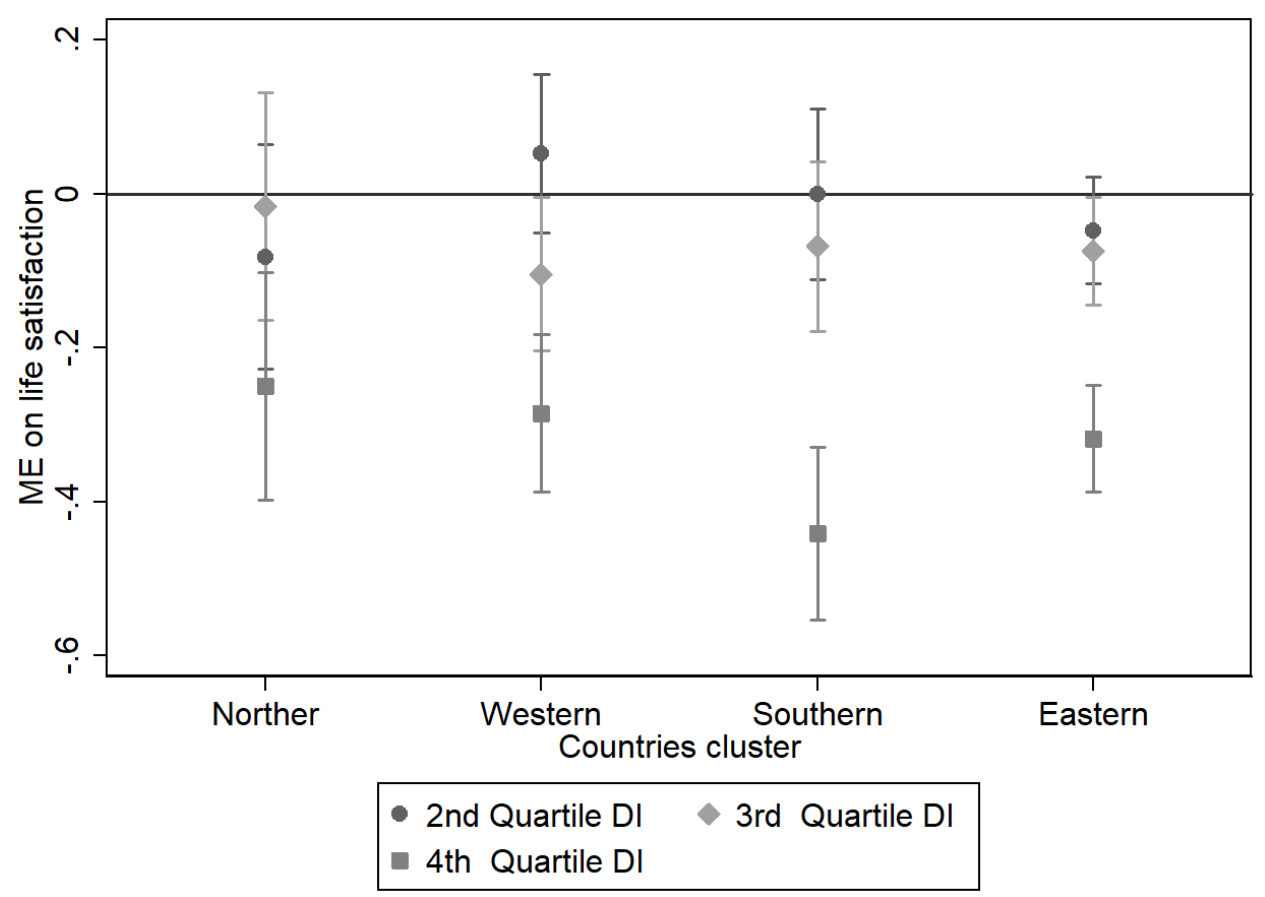

Note: The graph plots the marginal effect of the dissimilarity index quartiles (compared to the first one) on life satisfactions by country group obtained from a model that includes interactions with country group and where all control variables are included (estimated coefficients are reported in Table S.4 of the Supplementary Materials). 


\section{Supplementary Materials}

Table S.1. Linear regression model for the effect on life satisfaction of the quartiles of the dissimilarity index. (Full estimates of the baseline model)

\begin{tabular}{|c|c|c|}
\hline Independent variables & beta & s.e. \\
\hline \multicolumn{3}{|c|}{ Quartiles dissimilarity index (ref. Quartile 1) } \\
\hline Quartile 2 & $-0.06^{*}$ & $(0.02)$ \\
\hline Quartile 3 & $-0.10 * * *$ & $(0.02)$ \\
\hline Quartile 4 & $-0.36 * * *$ & $(0.03)$ \\
\hline \multicolumn{3}{|l|}{ Gender (ref. Man) } \\
\hline Woman & 0.01 & $(0.02)$ \\
\hline Age & 0.00 & $(0.00)$ \\
\hline \multicolumn{3}{|l|}{ Country (ref. Estonia) } \\
\hline Austria & $1.33 * * *$ & $(0.05)$ \\
\hline Germany & $0.91 * * *$ & $(0.05)$ \\
\hline Sweden & $1.21 * * *$ & $(0.06)$ \\
\hline Spain & $0.95 * * *$ & $(0.05)$ \\
\hline Italy & $0.83 * * *$ & $(0.05)$ \\
\hline France & $0.53 * * *$ & $(0.06)$ \\
\hline Denmark & $1.36 * * *$ & $(0.06)$ \\
\hline Greece & -0.06 & $(0.07)$ \\
\hline Switzerland & $1.55 * * *$ & $(0.07)$ \\
\hline Belgium & $0.71 * * *$ & $(0.05)$ \\
\hline Czech Republic & $0.63 * * *$ & $(0.05)$ \\
\hline Poland & $0.68 * * *$ & $(0.05)$ \\
\hline Luxembourg & $1.19 * * *$ & $(0.08)$ \\
\hline Hungary & -0.08 & $(0.06)$ \\
\hline Portugal & $0.89 * * *$ & $(0.10)$ \\
\hline Slovenia & $0.53 * * *$ & $(0.05)$ \\
\hline Croatia & $0.32 * * *$ & $(0.06)$ \\
\hline Lithuania & $-0.52 * * *$ & $(0.06)$ \\
\hline Bulgaria & $-0.85 * * *$ & $(0.06)$ \\
\hline Cyprus & $0.91 * * *$ & $(0.07)$ \\
\hline Finland & $1.34 * * *$ & $(0.06)$ \\
\hline Latvia & $-0.39 * * *$ & $(0.07)$ \\
\hline Malta & $1.35 * * *$ & $(0.07)$ \\
\hline Romania & $0.58 * * *$ & $(0.06)$ \\
\hline Slovakia & $0.46 * * *$ & $(0.06)$ \\
\hline \multicolumn{3}{|l|}{ Cohort (ref. 1932-1940) } \\
\hline $1941-1950$ & $0.15 * * *$ & $(0.03)$ \\
\hline $1951-1962$ & $0.13 *$ & $(0.03)$ \\
\hline \multicolumn{3}{|c|}{$\%$ of years being employed (ref. $75 \%-100 \%$ ) } \\
\hline $50 \%-74 \%$ & $-0.22 * * *$ & $(0.02)$ \\
\hline Less than $50 \%$ & $-0.38 * * *$ & $(0.03)$ \\
\hline \multicolumn{3}{|c|}{ Educational status (ref. ISCED $<3$ ) } \\
\hline ISCED 3 or 4 & $0.25 * * *$ & $(0.02)$ \\
\hline ISCED > 4 & $0.47 * * *$ & $(0.03)$ \\
\hline
\end{tabular}


Living with biological parents at 10 (ref. both biological)

Only one biological parent

$-0.03$

None biological parent

0.06

No information

0.04

$(0.40)$

Occupation of main breadwinner at 10 (ref. Managerial, professional, skilled non-manual)

Skilled manual

$-0.06^{*}$

Semi-skilled \& unskilled manual

0.04

Other

0.01

No information

$-0.02$

Overcrowding rate of the household at 10 (ref. 1 or less)

More than 1 to 1.5

$0.05 \dagger$

More than 1.5 to 2

$-0.01$

More than 2

$-0.03$

No information

$-0.43 * * *$

Self-defined health at childhood (ref. Excellent)

Very good

$-0.25 * * * \quad(0.02)$

Good

$-0.43 * * *$

Fair

$-0.65 * * *$

Poor

$-0.73 * * *$

Health varied a great deal

$-0.51 * *$

Constant

$7.03 * * *$

(0.06)

$\mathrm{N} \quad 42,754$

Note: $\uparrow \mathrm{p}<0.1 ; * \mathrm{p}<0.05, * * \mathrm{p}<0.01, * * * \mathrm{p}<0.001$. Standard errors (s.e.) in parentheses. Marginal effects of the dissimilarity index quartiles (compared to the first quartile) are graphically represented in Figure 1. 
Table S.2. Linear regression model for the effect on life satisfaction of the quartiles of the dissimilarity index with interactions with gender.

\begin{tabular}{|c|c|c|}
\hline Independent variables & beta & s.e. \\
\hline \multicolumn{3}{|c|}{ Quartiles dissimilarity index (ref. Quartile 1) } \\
\hline Quartile 2 & -0.04 & $(0.04)$ \\
\hline Quartile 3 & $-0.12 * *$ & $(0.04)$ \\
\hline Quartile 4 & $-0.37 * * *$ & $(0.04)$ \\
\hline \multicolumn{3}{|l|}{ Gender (ref. Man) } \\
\hline Woman & 0.01 & $(0.04)$ \\
\hline \multicolumn{3}{|c|}{ Quartiles dissimilarity index \# Gender } \\
\hline Quartile 2 \# Woman & -0.03 & $(0.05)$ \\
\hline Quartile 3 \# Woman & 0.02 & $(0.05)$ \\
\hline Quartile 4 \# Woman & 0.02 & $(0.05)$ \\
\hline Age & 0.00 & $(0.00)$ \\
\hline \multicolumn{3}{|l|}{ Country (ref. Estonia) } \\
\hline Austria & $1.33 * * *$ & $(0.05)$ \\
\hline Germany & $0.91 * * *$ & $(0.05)$ \\
\hline Sweden & $1.21 * * *$ & $(0.06)$ \\
\hline Spain & $0.95 * * *$ & $(0.05)$ \\
\hline Italy & $0.83 * * *$ & $(0.05)$ \\
\hline France & $0.53 * * *$ & $(0.06)$ \\
\hline Denmark & $1.36 * * *$ & $(0.06)$ \\
\hline Greece & -0.06 & $(0.07)$ \\
\hline Switzerland & $1.55 * * *$ & $(0.07)$ \\
\hline Belgium & $0.71 * * *$ & $(0.05)$ \\
\hline Czech Republic & $0.63 * * *$ & $(0.05)$ \\
\hline Poland & $0.68 * * *$ & $(0.05)$ \\
\hline Luxembourg & $1.19 * * *$ & $(0.08)$ \\
\hline Hungary & -0.08 & $(0.06)$ \\
\hline Portugal & $0.89 * * *$ & $(0.10)$ \\
\hline Slovenia & $0.53 * * *$ & $(0.05)$ \\
\hline Croatia & $0.32 * * *$ & $(0.06)$ \\
\hline Lithuania & $-0.52 * * *$ & $(0.06)$ \\
\hline Bulgaria & $-0.85 * * *$ & $(0.06)$ \\
\hline Cyprus & $0.91 * * *$ & $(0.07)$ \\
\hline Finland & $1.34 * * *$ & $(0.06)$ \\
\hline Latvia & $-0.39 * * *$ & $(0.07)$ \\
\hline Malta & $1.35 * * *$ & $(0.07)$ \\
\hline Romania & $0.58 * * *$ & $(0.06)$ \\
\hline Slovakia & $0.46 * * *$ & $(0.06)$ \\
\hline \multicolumn{3}{|l|}{ Cohort (ref. 1932-1940) } \\
\hline $1941-1950$ & $0.15 * * *$ & $(0.04)$ \\
\hline 1951-1962 & $0.13^{*}$ & $(0.06)$ \\
\hline \multicolumn{3}{|c|}{$\%$ of years being employed (ref. $75 \%-100 \%$ ) } \\
\hline $50 \%-74 \%$ & $-0.22 * * *$ & $(0.02)$ \\
\hline Less than $50 \%$ & $-0.38 * * *$ & $(0.03)$ \\
\hline
\end{tabular}


ISCED 3 or 4

$0.25 * * *$

$(0.02)$

ISCED $>4$

$0.47 * * *$

$(0.03)$

Living with biological parents at 10 (ref. both biological)

Only one biological parent

$-0.03$

None biological parent

0.06

$(0.07)$

No information

0.04

$(0.40)$

Occupation of main breadwinner at 10 (ref. Managerial, professional, skilled non-manual)

Skilled manual

$-0.06^{*}$

Semi-skilled \& unskilled manual

0.04

Other

0.01

No information

$-0.02$

Overcrowding rate of the household at 10 (ref. 1 or less)

More than 1 to 1.5

$0.05 \dagger$

More than 1.5 to 2

$-0.01$

More than 2

$-0.03$

No information

Self-defined health at childhood (ref. Excellent)

$-0.43 * * *$

Very good

$-0.25 * * * \quad(0.02)$

Good

$-0.43 * * *$

Fair

$-0.65 * * *$

Poor

$-0.73 * * *$

Health varied a great deal

$-0.51 * *$

Constant

$7.03 * * *$ $(0.24)$

42,754

Note: $\dagger \mathrm{p}<0.1 ; * \mathrm{p}<0.05, * * \mathrm{p}<0.01, * * * \mathrm{p}<0.001$. Standard errors (s.e.) in parentheses. Marginal effects of the dissimilarity index quartiles (compared to the first quartile) by gender are graphically represented in Figure 2. 
Table S.3. Linear regression model for the effect on life satisfaction of the quartiles of the dissimilarity index with interactions with education.

\begin{tabular}{|c|c|c|}
\hline Independent variables & beta & s.e. \\
\hline \multicolumn{3}{|c|}{ Quartiles dissimilarity index (ref. Quartile 1) } \\
\hline Quartile 2 & -0.06 & $(0.04)$ \\
\hline Quartile 3 & $-0.09 *$ & $(0.04)$ \\
\hline Quartile 4 & $-0.43 * * *$ & $(0.04)$ \\
\hline \multicolumn{3}{|c|}{ Educational status (ref. ISCED $<3$ ) } \\
\hline ISCED 3 or 4 & $0.23 * * *$ & $(0.04)$ \\
\hline ISCED $>4$ & $0.44 * * *$ & $(0.05)$ \\
\hline \multicolumn{3}{|c|}{ Quartiles dissimilarity index \# Gender } \\
\hline Quartile 2 \# ISCED 3 or 4 & 0.00 & $(0.06)$ \\
\hline Quartile 2 \# ISCED > 4 & 0.03 & $(0.07)$ \\
\hline Quartile 3 \# ISCED 3 or 4 & -0.04 & $(0.06)$ \\
\hline Quartile 3 \# ISCED > 4 & 0.01 & $(0.07)$ \\
\hline Quartile 4 \# ISCED 3 or 4 & $0.11 *$ & $(0.06)$ \\
\hline Quartile 4 \# ISCED > 4 & $0.10 \dagger$ & $(0.07)$ \\
\hline \multicolumn{3}{|l|}{ Gender (ref. Man) } \\
\hline Woman & 0.01 & $(0.02)$ \\
\hline Age & 0.00 & $(0.00)$ \\
\hline \multicolumn{3}{|l|}{ Country (ref. Estonia) } \\
\hline Austria & $1.33 * * *$ & $(0.05)$ \\
\hline Germany & $0.91 * * *$ & $(0.05)$ \\
\hline Sweden & $1.21 * * *$ & $(0.06)$ \\
\hline Spain & $0.95 * * *$ & $(0.05)$ \\
\hline Italy & $0.83 * * *$ & $(0.05)$ \\
\hline France & $0.53 * * *$ & $(0.06)$ \\
\hline Denmark & $1.36 * * *$ & $(0.06)$ \\
\hline Greece & -0.06 & $(0.07)$ \\
\hline Switzerland & $1.55 * * *$ & $(0.07)$ \\
\hline Belgium & $0.71 * * *$ & $(0.05)$ \\
\hline Czech Republic & $0.63 * * *$ & $(0.05)$ \\
\hline Poland & $0.68 * * *$ & $(0.05)$ \\
\hline Luxembourg & $1.19 * * *$ & $(0.08)$ \\
\hline Hungary & -0.08 & $(0.06)$ \\
\hline Portugal & $0.89 * * *$ & $(0.10)$ \\
\hline Slovenia & $0.53 * * *$ & $(0.05)$ \\
\hline Croatia & $0.32 * * *$ & $(0.06)$ \\
\hline Lithuania & $-0.52 * * *$ & $(0.06)$ \\
\hline Bulgaria & $-0.85 * * *$ & $(0.06)$ \\
\hline Cyprus & $0.91 * * *$ & $(0.07)$ \\
\hline Finland & $1.34 * * *$ & $(0.06)$ \\
\hline Latvia & $-0.39 * * *$ & $(0.07)$ \\
\hline Malta & $1.35 * * *$ & $(0.07)$ \\
\hline Romania & $0.58 * * *$ & $(0.06)$ \\
\hline Slovakia & $0.46^{* * * *}$ & $(0.06)$ \\
\hline
\end{tabular}


1941-1950

$0.15 * * *$

$(0.04)$

1951-1962

$0.13 *$

(0.06)

$\%$ of years being employed (ref. 75\%-100\%)

$50 \%-74 \%$

$-0.22 * * *$

Less than $50 \%$

Living with biological parents at 10 (ref. both biological)

Only one biological parent

$-0.03$

None biological parent

0.06

No information

0.02

$(0.40)$

Occupation of main breadwinner at 10 (ref. Managerial, professional, skilled non-manual)

Skilled manual

$-0.06^{*} \quad(0.03)$

Semi-skilled \& unskilled manual

0.04

Other

0.01

No information

$-0.02$

Overcrowding rate of the household at 10 (ref. 1 or less)

More than 1 to 1.5

$0.05 \dagger$

More than 1.5 to 2

$-0.01$

More than 2

$-0.03$

No information

$-0.42 * * *$

Self-defined health at childhood (ref. Excellent)

Very good

$-0.25 * * * \quad(0.02)$

Good

$-0.43 * * *$

Fair

$-0.65 * * *$

Poor

$-0.73 * * *$

Health varied a great deal

$-0.51 * *$

$7.05 * * *$

$(0.24)$

\section{$\mathrm{N}$} 42,754

Note: $\dagger p<0.1 ;{ }^{*} p<0.05,{ }^{* *} \mathrm{p}<0.01,{ }^{* * *} \mathrm{p}<0.001$. Standard errors (s.e.) in parentheses. Marginal effects of the dissimilarity index quartiles (compared to the first quartile) by education are graphically represented in Figure 3 . 
Table S.4. Linear regression model for the effect on life satisfaction of the quartiles of the dissimilarity index with interactions with country groups.

\begin{tabular}{|c|c|c|}
\hline Independent variables & beta & s.e. \\
\hline \multicolumn{3}{|c|}{ Quartiles dissimilarity index (ref. Quartile 1) } \\
\hline Quartile 2 & -0.06 & $(0.08)$ \\
\hline Quartile 3 & 0.00 & $(0.08)$ \\
\hline Quartile 4 & $-0.26 * * *$ & $(0.08)$ \\
\hline \multicolumn{3}{|l|}{ Country group (ref. Northern) } \\
\hline Western & $-0.32 * * *$ & $(0.07)$ \\
\hline Southern & $-0.43 * * *$ & $(0.07)$ \\
\hline Eastern & $-1.09 * * *$ & $(0.06)$ \\
\hline \multicolumn{3}{|l|}{ Quartiles dissimilarity index \# Gender } \\
\hline Quartile 2 \# Western & 0.12 & $(0.09)$ \\
\hline Quartile 2 \# Southern & 0.05 & $(0.10)$ \\
\hline Quartile 2 \# Eastern & 0.01 & $(0.08)$ \\
\hline Quartile 3 \# Western & -0.12 & $(0.09)$ \\
\hline Quartile 3 \# Southern & -0.12 & $(0.10)$ \\
\hline Quartile 3 \# Eastern & -0.08 & $(0.09)$ \\
\hline Quartile 4 \# Western & -0.03 & $(0.09)$ \\
\hline Quartile 4 \# Southern & $-0.22 *$ & $(0.10)$ \\
\hline Quartile 4 \# Eastern & -0.07 & $(0.09)$ \\
\hline \multicolumn{3}{|l|}{ Gender (ref. Man) } \\
\hline Woman & -0.01 & $(0.02)$ \\
\hline Age & 0.00 & $(0.00)$ \\
\hline \multicolumn{3}{|l|}{ Cohort (ref. 1932-1940) } \\
\hline $1941-1950$ & $0.19 * * *$ & $(0.04)$ \\
\hline $1951-1962$ & $0.20 * *$ & $(0.06)$ \\
\hline \multicolumn{3}{|c|}{$\%$ of years being employed (ref. $75 \%-100 \%$ ) } \\
\hline $50 \%-74 \%$ & $-0.20 * * *$ & $(0.02)$ \\
\hline Less than $50 \%$ & $-0.32 * * *$ & $(0.03)$ \\
\hline \multicolumn{3}{|l|}{ Educational status (ref. ISCED $<3$ ) } \\
\hline ISCED 3 or 4 & $0.28 * * *$ & $(0.02)$ \\
\hline ISCED > 4 & $0.42 * * *$ & $(0.03)$ \\
\hline \multicolumn{3}{|c|}{ Living with biological parents at 10 (ref. both biological) } \\
\hline Only one biological parent & -0.04 & $(0.03)$ \\
\hline None biological parent & 0.05 & $(0.07)$ \\
\hline No information & 0.30 & $(0.41)$ \\
\hline \multicolumn{3}{|c|}{$\begin{array}{l}\text { Occupation of main breadwinner at } 10 \text { (ref. Managerial, } \\
\text { professional, skilled non-manual) }\end{array}$} \\
\hline Skilled manual & 0.00 & $(0.03)$ \\
\hline Semi-skilled \& unskilled manual & $0.08^{* *}$ & $(0.02)$ \\
\hline Other & 0.03 & $(0.04)$ \\
\hline No information & $-0.09 * *$ & $(0.03)$ \\
\hline \multicolumn{3}{|c|}{ Overcrowding rate of the household at 10 (ref. 1 or less) } \\
\hline More than 1 to 1.5 & $0.05 \dagger$ & $(0.03)$ \\
\hline More than 1.5 to 2 & 0.02 & $(0.03)$ \\
\hline
\end{tabular}


More than 2

$0.05 \dagger \quad(0.03)$

No information

$-0.39 * * *$

$(0.11)$

Self-defined health at childhood (ref. Excellent)

Very good

$-0.17 * * * \quad(0.02)$

Good

$-0.39 * * *$

Fair

$-0.65 * * *$

Poor

$-0.73 * * *$

(0.06)

Health varied a great deal

$-0.48 *$

$(0.19)$

Constant

$8.16^{* * * *}$

$\mathrm{N}$

42,754

Note: $\uparrow \mathrm{p}<0.1 ; * \mathrm{p}<0.05, * * \mathrm{p}<0.01, * * * \mathrm{p}<0.001$. Standard errors (s.e.) in parentheses. Marginal effects of the dissimilarity index quartiles (compared to the first quartile) by country are graphically represented in Figure 4. 
Table S.5. Linear regression model for the effect on life satisfaction of the quartiles of the dissimilarity index adding additional controls for partner and children death occurrence and timing.

\begin{tabular}{|c|c|c|}
\hline Independent variables & beta & s.e. \\
\hline \multicolumn{3}{|c|}{ Quartiles dissimilarity index (ref. Quartile 1) } \\
\hline Quartile 2 & $-0.04 \uparrow$ & $(0.02)$ \\
\hline Quartile 3 & $-0.08 * * *$ & $(0.02)$ \\
\hline Quartile 4 & $-0.35 * * *$ & $(0.02)$ \\
\hline \multicolumn{3}{|c|}{ Time since death of a child (ref. never) } \\
\hline$<6$ years & $-0.53 * * *$ & $(0.08)$ \\
\hline $6-10$ years & $-0.69 * * *$ & $(0.10)$ \\
\hline $11-20$ years & $-0.45 * * *$ & $(0.08)$ \\
\hline$>20$ years & $-0.09 \dagger$ & $(0.05)$ \\
\hline \multicolumn{3}{|c|}{ Time since death of partner (ref. never) } \\
\hline$<6$ years & $-0.56 * * *$ & $(0.04)$ \\
\hline $6-10$ years & $-0.40 * * *$ & $(0.05)$ \\
\hline 11-20 years & $-0.31 * * *$ & $(0.05)$ \\
\hline$>20$ years & $-0.27 * * *$ & $(0.05)$ \\
\hline \multicolumn{3}{|l|}{ Gender (ref. Man) } \\
\hline Women & $0.07 * * *$ & $(0.02)$ \\
\hline Age & $0.01 *$ & $(0.00)$ \\
\hline \multicolumn{3}{|l|}{ Country (ref. Estonia) } \\
\hline Austria & $1.29 * * *$ & $(0.05)$ \\
\hline Germany & $0.88 * * *$ & $(0.05)$ \\
\hline Sweden & $1.15 * * *$ & $(0.06)$ \\
\hline Spain & $0.88 * * *$ & $(0.05)$ \\
\hline Italy & $0.77 * * *$ & $(0.05)$ \\
\hline France & $0.50 * * *$ & $(0.06)$ \\
\hline Denmark & $1.33 * * *$ & $(0.06)$ \\
\hline Greece & -0.10 & $(0.07)$ \\
\hline Switzerland & $1.49 * * *$ & $(0.07)$ \\
\hline Belgium & $0.67 * * *$ & $(0.05)$ \\
\hline Czech Republic & $0.61 * * *$ & $(0.05)$ \\
\hline Poland & $0.65 * * *$ & $(0.05)$ \\
\hline Luxembourg & $1.15^{* * *}$ & $(0.08)$ \\
\hline Hungary & -0.08 & $(0.06)$ \\
\hline Portugal & $0.82 * * *$ & $(0.10)$ \\
\hline Slovenia & $0.50 * * *$ & $(0.05)$ \\
\hline Croatia & $0.29 * * *$ & $(0.06)$ \\
\hline Lithuania & $-0.50 * * *$ & $(0.06)$ \\
\hline Bulgaria & $-0.84 * * *$ & $(0.06)$ \\
\hline
\end{tabular}


Cyprus

$$
\begin{array}{ll}
0.85 * * * & (0.07) \\
1.30 * * * & (0.06) \\
-0.36 * * * & (0.07) \\
1.27 * * * & (0.07) \\
0.58 * * * & (0.06) \\
0.44 * * * & (0.06)
\end{array}
$$

Finland

Latvia

Malta

Romania

Slovakia

Cohort (ref. 1932-1940)

1941-1950

$0.13^{* * *} \quad(0.04)$

1951-1962

$0.12 \dagger$

$\%$ of years being employed (ref. $75 \%-100 \%$ )

$50-74 \%$

$-0.21 * * * \quad(0.02)$

less than $50 \%$

$-0.36^{* * *} \quad(0.03)$

Educational status (ref. ISCED $<3$ )

ISCED 3 or 4

$$
\begin{array}{ll}
0.23 * * * & (0.02) \\
0.44 * * * & (0.03)
\end{array}
$$

ISCED > 4

Living with biological parents at 10 (ref. both biological)

Only one biological parent

$-0.03 \quad(0.03)$

No information

0.02

$(0.40)$

Occupation of main breadwinner at 10 (ref. Managerial, professional, skilled non-manual)

Skilled manual

$-0.06^{*} \quad(0.03)$

Semi-skilled \& unskilled manual

$0.04 \dagger$

Other

0.02

No information

$-0.01$

Overcrowding rate of the household at 10 (ref. 1 or less)

More than 1 to 1.5

$0.04 \quad(0.03)$

More than 1.5 to 2

$-0.01$

More than 2

$-0.03$

No information

$-0.40 * * *$

Self-defined health at childhood (ref. Excellent)

Very good

$$
\begin{array}{ll}
-0.25 * * * & (0.02) \\
-0.43 * * * & (0.02) \\
-0.66 * * * & (0.04) \\
-0.75 * * * & (0.06) \\
-0.55 * * & (0.19)
\end{array}
$$

Good

Fair

Poor

Health varied a great deal

Constant

$6.77 * * *$

42,696

Note: $\uparrow \mathrm{p}<0.1 ;{ }^{*} \mathrm{p}<0.05,{ }^{* *} \mathrm{p}<0.01,{ }^{* * *} \mathrm{p}<0.001$. Standard errors (s.e.) in parentheses. The model differs from the baseline model (Table S.1) for the inclusion of additional controls: Time since death of a child, Time since death of partner. 
Table S.6a. Linear regression model for the effect on quality of life (CASP) of the quartiles of the dissimilarity index.

\begin{tabular}{|c|c|c|}
\hline Independent variables & beta & s.e. \\
\hline \multicolumn{3}{|c|}{ Quartiles dissimilarity index (ref. Quartile 1) } \\
\hline Quartile 2 & $-0.24 * *$ & $(0.08)$ \\
\hline Quartile 3 & $-0.45 * * *$ & $(0.08)$ \\
\hline Quartile 4 & $-1.08 * * *$ & $(0.08)$ \\
\hline \multicolumn{3}{|l|}{ Gender (ref. Man) } \\
\hline Woman & -0.10 & $(0.06)$ \\
\hline Age & $-0.06 * * *$ & $(0.01)$ \\
\hline \multicolumn{3}{|l|}{ Country (ref. Estonia) } \\
\hline Austria & $4.04 * * *$ & $(0.17)$ \\
\hline Germany & $2.44 * * *$ & $(0.17)$ \\
\hline Sweden & $2.47 * * *$ & $(0.18)$ \\
\hline Spain & $1.35 * * *$ & $(0.17)$ \\
\hline Italy & $-0.53 * *$ & $(0.17)$ \\
\hline France & $1.99 * * *$ & $(0.19)$ \\
\hline Denmark & $3.50 * * *$ & $(0.20)$ \\
\hline Greece & $-4.36 * * *$ & $(0.23)$ \\
\hline Switzerland & $4.33 * * *$ & $(0.21)$ \\
\hline Belgium & $1.21 * * *$ & $(0.17)$ \\
\hline Czech Republic & $-0.60 * * *$ & $(0.16)$ \\
\hline Poland & $0.68 * * *$ & $(0.16)$ \\
\hline Luxembourg & $4.17 * * *$ & $(0.25)$ \\
\hline Hungary & $-0.70 * * *$ & $(0.20)$ \\
\hline Portugal & $-1.29 * * *$ & $(0.32)$ \\
\hline Slovenia & $2.52 * * *$ & $(0.16)$ \\
\hline Croatia & -0.17 & $(0.19)$ \\
\hline Lithuania & $-3.64 * * *$ & $(0.20)$ \\
\hline Bulgaria & $-3.86^{* * *}$ & $(0.19)$ \\
\hline Cyprus & $-0.58 *$ & $(0.23)$ \\
\hline Finland & $1.36 * * *$ & $(0.19)$ \\
\hline Latvia & $-1.86 * * *$ & $(0.23)$ \\
\hline Malta & $1.73 * * *$ & $(0.22)$ \\
\hline Romania & $-3.17 * * *$ & $(0.19)$ \\
\hline Slovakia & $-0.97 * * *$ & $(0.19)$ \\
\hline \multicolumn{3}{|l|}{ Cohort (ref. 1932-1940) } \\
\hline $1941-1950$ & $1.19 * * *$ & $(0.12)$ \\
\hline 1951-1962 & $1.01 * * *$ & $(0.19)$ \\
\hline \multicolumn{3}{|c|}{$\%$ of years being employed (ref. $75 \%-100 \%$ ) } \\
\hline $50 \%-74 \%$ & $-0.87 * * *$ & $(0.07)$ \\
\hline Less than $50 \%$ & $-1.74 * * *$ & $(0.08)$ \\
\hline \multicolumn{3}{|c|}{ Educational status (ref. ISCED < 3) } \\
\hline ISCED 3 or 4 & $1.31 * * *$ & $(0.07)$ \\
\hline ISCED > 4 & $2.40 * * *$ & $(0.09)$ \\
\hline
\end{tabular}

Living with biological parents at 10 (ref. both biological) 
Only one biological parent

$-0.12$

None biological parent

$-0.32$

No information

$-1.40$

Occupation of main breadwinner at 10 (ref. Managerial, professional, skilled non-manual)

Skilled manual

$-0.13$

Semi-skilled \& unskilled manual

$-0.06$

Other

$-0.39 * *$

No information

0.04

Overcrowding rate of the household at 10 (ref. 1 or less)

More than 1 to 1.5

$0.07 \quad(0.08)$

More than 1.5 to 2

$-0.05$

More than 2

$-0.48 * * *$

No information

$-0.48$

Self-defined health at childhood (ref. Excellent)

Very good

$-1.00 * * * \quad(0.07)$

Good

$-1.80 * * *$

Fair

$-2.74 * * *$

Poor

$-3.35 * * *$

Health varied a great deal

$-1.79 * *$

Constant

$40.58 * * *$

$(0.76)$

$\mathrm{N} \quad 42,754$

Note: $\uparrow \mathrm{p}<0.1 ; * \mathrm{p}<0.05, * * \mathrm{p}<0.01, * * * \mathrm{p}<0.001$. Standard errors (s.e.) in parentheses. The model is the same as the baseline model (Table S.1) but for a different outcome: CASP. CASP is a measure of quality of life ranging from 4 to 48 (the higher the better). 
Table S.6b. Linear regression model for the effect on number of depressive symptoms (EUROD) of the quartiles of the dissimilarity index.

\begin{tabular}{|c|c|c|}
\hline Independent variables & beta & s.e. \\
\hline \multicolumn{3}{|c|}{ Quartiles dissimilarity index (ref. Quartile 1) } \\
\hline Quartile 2 & $0.13 * * *$ & $(0.04)$ \\
\hline Quartile 3 & $0.09 *$ & $(0.04)$ \\
\hline Quartile 4 & $0.32 * * *$ & $(0.04)$ \\
\hline \multicolumn{3}{|l|}{ Gender (ref. Man) } \\
\hline Woman & $0.59 * * *$ & $(0.03)$ \\
\hline Age & 0.00 & $(0.00)$ \\
\hline \multicolumn{3}{|l|}{ Country (ref. Estonia) } \\
\hline Austria & $-0.72 * * *$ & $(0.07)$ \\
\hline Germany & $-0.30 * * *$ & $(0.06)$ \\
\hline Sweden & $-0.47 * * *$ & $(0.07)$ \\
\hline Spain & $-0.53 * * *$ & $(0.07)$ \\
\hline Italy & -0.08 & $(0.06)$ \\
\hline France & -0.06 & $(0.06)$ \\
\hline Denmark & $-0.48 * * *$ & $(0.07)$ \\
\hline Greece & $0.23 * *$ & $(0.09)$ \\
\hline Switzerland & $-0.67 * * *$ & $(0.08)$ \\
\hline Belgium & 0.02 & $(0.07)$ \\
\hline Czech Republic & $-0.50 * * *$ & $(0.06)$ \\
\hline Poland & $0.36 * *$ & $(0.14)$ \\
\hline Luxembourg & $-0.23 *$ & $(0.10)$ \\
\hline Portugal & $0.43 * * *$ & $(0.12)$ \\
\hline Slovenia & $-0.57 * * *$ & $(0.06)$ \\
\hline Croatia & $-0.13 \dagger$ & $(0.07)$ \\
\hline \multicolumn{3}{|l|}{ Cohort (ref. 1932-1940) } \\
\hline $1941-1950$ & $-0.32 * * *$ & $(0.05)$ \\
\hline $1951-1962$ & $-0.19 *$ & $(0.09)$ \\
\hline \multicolumn{3}{|c|}{$\%$ of years being employed (ref. $75 \%-100 \%$ ) } \\
\hline $50 \%-74 \%$ & $0.25 * * *$ & $(0.03)$ \\
\hline Less than $50 \%$ & $0.58 * * *$ & $(0.04)$ \\
\hline \multicolumn{3}{|l|}{ Educational status (ref. ISCED $<3$ ) } \\
\hline ISCED 3 or 4 & $-0.29 * * *$ & $(0.03)$ \\
\hline ISCED > 4 & $-0.46 * * *$ & $(0.04)$ \\
\hline \multicolumn{3}{|c|}{ Living with biological parents at 10 (ref. both biological) } \\
\hline Only one biological parent & $0.16 * * *$ & $(0.04)$ \\
\hline None biological parent & $0.20 *$ & $(0.09)$ \\
\hline No information & -0.38 & $(0.83)$ \\
\hline \multicolumn{3}{|c|}{$\begin{array}{l}\text { Occupation of main breadwinner at } 10 \text { (ref. Managerial, } \\
\text { professional, skilled non-manual) }\end{array}$} \\
\hline Skilled manual & $-0.08 *$ & $(0.04)$ \\
\hline Semi-skilled \& unskilled manual & 0.02 & $(0.03)$ \\
\hline Other & 0.06 & $(0.05)$ \\
\hline No information & 0.03 & $(0.05)$ \\
\hline
\end{tabular}


Overcrowding rate of the household at 10 (ref. 1 or less)

More than 1 to 1.5

0.00

$(0.04)$

More than 1.5 to 2

0.02

More than 2

$0.20 * * *$

No information

$0.36 *$

$(0.15)$

Self-defined health at childhood (ref. Excellent)

Very good

$0.11 * * *$

$(0.03)$

Good

$0.37 * * *$

Fair

$0.81 * * *$

Poor

$0.93 * * *$

$(0.08)$

Health varied a great deal

0.37

Note: $\uparrow \mathrm{p}<0.1 ; * \mathrm{p}<0.05, * * \mathrm{p}<0.01, * * * \mathrm{p}<0.001$. Standard errors (s.e.) in parentheses. The model is the same as the baseline model (Table S.1) but for a different outcome: EUROD. The sample size is lower because fewer countries participated in wave 6 from which EUROD is taken. EUROD measures the number of self-reported depressive symptoms and ranges from 0 to 12 (the higher the more depressive symptoms). 
Table S.7. Instrumental variable linear regression model for the effect on life satisfaction of the quartiles of the dissimilarity index.

\begin{tabular}{|c|c|c|}
\hline Independent variables & beta & s.e. \\
\hline \multicolumn{3}{|c|}{ Quartiles dissimilarity index (ref. Quartile 1) } \\
\hline Quartile 2 & -0.18 & $(0.14)$ \\
\hline Quartile 3 & -0.11 & $(0.16)$ \\
\hline Quartile 4 & $-0.70 * * *$ & $(0.17)$ \\
\hline \multicolumn{3}{|l|}{ Gender (ref. Man) } \\
\hline Woman & 0.02 & $(0.02)$ \\
\hline Age & -0.00 & $(0.00)$ \\
\hline \multicolumn{3}{|l|}{ Country (ref. Estonia) } \\
\hline Austria & $1.34 * * *$ & $(0.05)$ \\
\hline Germany & $0.91 * * *$ & $(0.05)$ \\
\hline Sweden & $1.22 * * *$ & $(0.06)$ \\
\hline Spain & $0.96 * * *$ & $(0.05)$ \\
\hline Italy & $0.83 * * *$ & $(0.05)$ \\
\hline France & $0.53 * * *$ & $(0.06)$ \\
\hline Denmark & $1.37 * * *$ & $(0.06)$ \\
\hline Greece & -0.04 & $(0.07)$ \\
\hline Switzerland & $1.55 * * *$ & $(0.07)$ \\
\hline Belgium & $0.70 * * *$ & $(0.05)$ \\
\hline Czech Republic & $0.66 * * *$ & $(0.05)$ \\
\hline Poland & $0.68 * * *$ & $(0.06)$ \\
\hline Luxembourg & $1.17 * * *$ & $(0.08)$ \\
\hline Hungary & -0.08 & $(0.06)$ \\
\hline Portugal & $0.88 * * *$ & $(0.10)$ \\
\hline Slovenia & $0.55 * * *$ & $(0.05)$ \\
\hline Croatia & $0.33 * * *$ & $(0.06)$ \\
\hline Lithuania & $-0.50 * * *$ & $(0.06)$ \\
\hline Bulgaria & $-0.81 * * *$ & $(0.06)$ \\
\hline Cyprus & $0.88^{* * *}$ & $(0.08)$ \\
\hline Finland & $1.35^{* * *}$ & $(0.06)$ \\
\hline Latvia & $-0.39 * * *$ & $(0.07)$ \\
\hline Malta & $1.35 * * *$ & $(0.07)$ \\
\hline Romania & $0.56 * * *$ & $(0.06)$ \\
\hline Slovakia & $0.45 * * *$ & $(0.06)$ \\
\hline \multicolumn{3}{|l|}{ Cohort (ref. 1932-1940) } \\
\hline $1941-1950$ & $0.15 * * *$ & $(0.04)$ \\
\hline 1951-1962 & $0.13^{*}$ & $(0.06)$ \\
\hline \multicolumn{3}{|c|}{$\%$ of years being employed (ref. $75 \%-100 \%$ ) } \\
\hline $50 \%-74 \%$ & $-0.22 * * *$ & $(0.02)$ \\
\hline Less than $50 \%$ & $-0.39 * * *$ & $(0.03)$ \\
\hline \multicolumn{3}{|c|}{ Educational status (ref. ISCED $<3$ ) } \\
\hline ISCED 3 or 4 & $0.24 * * *$ & $(0.02)$ \\
\hline ISCED > 4 & $0.46 * * *$ & $(0.03)$ \\
\hline
\end{tabular}

Living with biological parents at 10 (ref. both biological) 
Only one biological parent

$-0.03$

$(0.03)$

None biological parent

0.06

$(0.07)$

No information

0.03

$(0.41)$

Occupation of main breadwinner at 10 (ref. Managerial, professional, skilled non-manual)

Skilled manual

$-0.07 *$

Semi-skilled \& unskilled manual

0.04

Other

0.01

No information

$-0.01$

Overcrowding rate of the household at 10 (ref. 1 or less)

More than 1 to 1.5

0.04

More than 1.5 to 2

$-0.02$

More than 2

$-0.04$

No information

$-0.40 * * *$

Self-defined health at childhood (ref. Excellent)

Very good

$-0.25 * * * \quad(0.02)$

Good

$-0.42 * * *$

Fair

$-0.64 * * *$

Poor

$-0.72 * * *$

Health varied a great deal

$-0.50^{* * *}$

$(0.19)$

Constant

$7.23 * * *$

$(0.27)$

42,754

N

Note: $\uparrow \mathrm{p}<0.1 ; * \mathrm{p}<0.05, * * \mathrm{p}<0.01, * * * \mathrm{p}<0.001$. Standard errors (s.e.) in parentheses. Estimates are from an instrumental variable linear regression model using internally generated instruments based on heteroscedasticity present in the data (Lewbel 2012). 
Table S.8. Linear regression models for the effect on life satisfaction of the quartiles of the dissimilarity index adding as independent variables specific measures of fertility and partnership histories.

\begin{tabular}{|c|c|c|c|c|c|c|c|c|}
\hline \multirow{2}{*}{ Independent variables } & \multicolumn{8}{|c|}{ Models } \\
\hline & (1) & $(2)$ & $(3)$ & $(4)$ & $(5)$ & $(6)$ & $(7)$ & $(8)$ \\
\hline \multicolumn{9}{|l|}{ Quartile dissimilarity index (ref. Quartile 1) } \\
\hline Quartile 2 & $\begin{array}{l}-0.06^{*} \\
(0.03)\end{array}$ & $\begin{array}{l}-0.04 \\
(0.02)\end{array}$ & $\begin{array}{l}-0.05^{*} \\
(0.02)\end{array}$ & $\begin{array}{l}-0.05^{*} \\
(0.02)\end{array}$ & $\begin{array}{l}-0.06^{*} \\
(0.03)\end{array}$ & $\begin{array}{l}-0.08 * * \\
(0.03)\end{array}$ & $\begin{array}{l}-0.02 \\
(0.02)\end{array}$ & $\begin{array}{l}-0.04 \\
(0.03)\end{array}$ \\
\hline Quartile 3 & $\begin{array}{l}-0.11 * * * \\
(0.03)\end{array}$ & $\begin{array}{l}-0.06^{*} \\
(0.02)\end{array}$ & $\begin{array}{l}-0.10 * * * \\
(0.02)\end{array}$ & $\begin{array}{l}-0.10 * * * \\
(0.02)\end{array}$ & $\begin{array}{l}-0.10 * * * \\
(0.03)\end{array}$ & $\begin{array}{l}-0.14 * * * \\
(0.03)\end{array}$ & $\begin{array}{l}-0.05 \dagger \\
(0.03)\end{array}$ & $\begin{array}{l}-0.05 \dagger \\
(0.03)\end{array}$ \\
\hline Quartile 4 & $\begin{array}{l}-0.29 * * * \\
(0.03)\end{array}$ & $\begin{array}{l}-0.30 * * * \\
(0.03)\end{array}$ & $\begin{array}{l}-0.32 * * * \\
(0.03)\end{array}$ & $\begin{array}{l}-0.35 * * * \\
(0.03)\end{array}$ & $\begin{array}{l}-0.32 * * * \\
(0.03)\end{array}$ & $\begin{array}{l}-0.35 * * * \\
(0.03)\end{array}$ & $\begin{array}{l}-0.17 \text { *** } \\
(0.03)\end{array}$ & $\begin{array}{l}-0.13 * * * \\
(0.03)\end{array}$ \\
\hline \multicolumn{9}{|c|}{ Age 1st time living with partner (ref. 2 nd tercile) } \\
\hline 1st tercile & $\begin{array}{l}0.01 \\
(0.02)\end{array}$ & & & & & & & $\begin{array}{l}-0.00 \\
(0.03)\end{array}$ \\
\hline 3rd tercile & $\begin{array}{l}-0.04 \\
(0.02)\end{array}$ & & & & & & & $\begin{array}{l}-0.01 \\
(0.03)\end{array}$ \\
\hline Never lived with partner & $\begin{array}{l}-0.40 * * * \\
(0.05)\end{array}$ & & & & & & & $\begin{array}{l}-0.42 * * * \\
(0.05)\end{array}$ \\
\hline Experience a divorce/ separation (ref. No) & & $\begin{array}{l}-0.28 * * * \\
(0.02)\end{array}$ & & & & & & $\begin{array}{l}-0.33^{* * * *} \\
(0.03)\end{array}$ \\
\hline Experience cohabitation (ref. No) & & & $\begin{array}{l}-0.19 * * * \\
(0.04)\end{array}$ & & & & & $\begin{array}{l}-0.19 * * * \\
(0.04)\end{array}$ \\
\hline Experienced re-partnering (ref. No) & & & & $\begin{array}{l}-0.05 \\
(0.03)\end{array}$ & & & & $\begin{array}{l}-0.05 \\
(0.03)\end{array}$ \\
\hline \multicolumn{9}{|l|}{ Age 1st child (ref. 2nd tercile) } \\
\hline 1 st tercile & & & & & $\begin{array}{l}-0.01 \\
(0.02)\end{array}$ & & & \\
\hline 3rd tercile & & & & & $\begin{array}{l}-0.04 \dagger \\
(0.02)\end{array}$ & & & \\
\hline No children & & & & & $\begin{array}{l}-0.12^{* *} \\
(0.04)\end{array}$ & & & \\
\hline
\end{tabular}


Number of children (age 49) (ref. 2)

3 or more children

\section{Children out of wedlock (ref. No)}

Yes

No children

Children combined variable (ref. all within wedlock; $n<=2$; 3rd tercile)

No children

At least one child out of wedlock

All within wedlock; $\mathrm{n}<=2$; first tercile

All within wedlock; $\mathrm{n}<=2$; second tercile

All within wedlock; $\mathrm{n}>2$; first tercile

All within wedlock; $n>2$; second tercile

All within wedlock; $\mathrm{n}>2$; third tercile children out of wedlock, had children all within wedlock. The latter group is further split according to number of children (whether bigger than 2 or not) and age at the first child (in terciles). 